\title{
The Effect of Anticoagulants, Temperature, and Time on the Human Plasma Metabolome and Lipidome from Healthy Donors as Determined by Liquid Chromatography-Mass Spectrometry
}

\author{
Manoj Khadka ${ }^{1,2} \oplus$, Andrei Todor ${ }^{3}$, Kristal M. Maner-Smith ${ }^{1}$, Jennifer K. Colucci ${ }^{1,2}$, \\ ViLinh Tran ${ }^{3}$, David A. Gaul ${ }^{4}$ (D), Evan J. Anderson 3,5, Muktha S. Natrajan ${ }^{3}$, Nadine Rouphael ${ }^{3}$, \\ Mark J. Mulligan ${ }^{3}$, Circe E. McDonald ${ }^{5}$, Mehul Suthar ${ }^{5}$, Shuzhao Li ${ }^{3}$ and Eric A. Ortlund ${ }^{1,2, *(D)}$ \\ 1 Emory Integrated Lipidomics Core, Emory University School of Medicine, Atlanta, GA 30322, USA; \\ manoj.khadka@emory.edu (M.K.); kristal.m.maner-smith@emory.edu (K.M.M.-S.); \\ jennifer.k.colucci@emory.edu (J.K.C.) \\ 2 Department of Biochemistry, Emory University School of Medicine, Atlanta, GA 30322, USA \\ 3 Department of Medicine, Emory University School of Medicine, Atlanta, GA 30322, USA; \\ andrei.todor@emory.edu (A.T.); vilinh.tran@emory.edu (V.T.); evanderson@emory.edu (E.J.A.); \\ muktha.natrajan@emory.edu (M.S.N.); nroupha@emory.edu (N.R.); \\ mark.mulligan@nyulangone.org (M.J.M.); sli49@emory.edu (S.L.) \\ 4 School of Chemistry and Biochemistry, Georgia Institute of Technology, Atlanta, GA 30332, USA; \\ david.gaul@chemistry.gatech.edu \\ 5 Department of Paediatrics, Emory University School of Medicine, Atlanta, GA 30322, USA; \\ circemcd@gmail.com (C.E.M.); mehul.s.suthar@emory.edu (M.S.) \\ * Correspondence: eortlun@emory.edu
}

Received: 18 April 2019; Accepted: 21 May 2019; Published: 23 May 2019

\begin{abstract}
Liquid-chromatography mass spectrometry is commonly used to identify and quantify metabolites from biological samples to gain insight into human physiology and pathology. Metabolites and their abundance in biological samples are labile and sensitive to variations in collection conditions, handling and processing. Variations in sample handling could influence metabolite levels in ways not related to biology, ultimately leading to the misinterpretation of results. For example, anticoagulants and preservatives modulate enzyme activity and metabolite oxidization. Temperature may alter both enzymatic and non-enzymatic chemistry. The potential for variation induced by collection conditions is particularly important when samples are collected in remote locations without immediate access to specimen processing. Data are needed regarding the variation introduced by clinical sample collection processes to avoid introducing artifact biases. In this study, we used metabolomics and lipidomics approaches paired with univariate and multivariate statistical analyses to assess the effects of anticoagulant, temperature, and time on healthy human plasma samples collected to provide guidelines on sample collection, handling, and processing for vaccinology. Principal component analyses demonstrated clustering by sample collection procedure and that anticoagulant type had the greatest effect on sample metabolite variation. Lipids such as glycerophospholipids, acylcarnitines, sphingolipids, diacylglycerols, triacylglycerols, and cholesteryl esters are significantly affected by anticoagulant type as are amino acids such as aspartate, histidine, and glutamine. Most plasma metabolites and lipids were unaffected by storage time and temperature. Based on this study, we recommend samples be collected using a single anticoagulant (preferably EDTA) with sample processing at $<24 \mathrm{~h}$ at $4{ }^{\circ} \mathrm{C}$.
\end{abstract}

Keywords: lipidomics; metabolomics; anticoagulants; vaccine; storage conditions; sample collection 


\section{Introduction}

Recent advancements in sensitive analytical technologies such as liquid-chromatography mass spectrometry (LC-MS) have enabled the identification and quantification of polar and non-polar metabolites in biological samples. Lipidomics approaches entail measuring and assessing the biological roles of the entire spectrum of lipid molecular species in a cell/tissue which can be influenced by expression of proteins involved in lipid metabolism and function, including gene regulation" [1]. Similarly, metabolomics refers to measuring the complete set of metabolites that change according to the physiological, developmental, or pathological state of the cell, tissue, organ, or organism [2]. Metabolomics and lipidomics approaches employ high-resolution mass spectrometry to profile thousands of chemical components in an array of biological samples, making it one of the most powerful technologies to investigate metabolic perturbations in normal biology, disease or other exogenous or endogenous factors. Recently, the Human Metabolome Database (http://www.hmdb.ca/) reported the classification of more than a hundred thousand metabolites [3] which was made possible due to advancement in analytical platforms and computational tools.

The hundreds of thousands of metabolites and lipids [3] that are synthesized via several hundred biochemical reactions drive biochemical processes such as signaling, membrane integrity, inflammation, homeostasis, and many other regulatory functions [4-11]. Cellular metabolic activities can be studied by quantifying changes in lipids at the class, subclass, and molecular species level and discerning the differential metabolites between normal and abnormal cells [12]. Several infectious and non-infectious diseases involve perturbation of biochemical pathways that are reflected in metabolite and lipid levels in tissues, blood, and other biological entities. Thus, change in the normal concentrations of these metabolites and lipids often relates to disease and differential physiological states [13-15].

Metabolites can be studied by two major approaches-untargeted and targeted-through utilization of different analytical platforms. Untargeted analyses attempt to broadly profile as many metabolites as possible, while targeted analyses specifically characterize metabolites based on their chemical properties [16]. LC-MS and gas chromatography-mass spectrometry (GC-MS) are most commonly used for comprehensively studying metabolites and lipids in both targeted and untargeted analyses. Although frequently used, the sensitivity and resolution of NMR are inferior to MS and only able to detect highly abundant metabolites [16]. However, MS platforms capture broad metabolite classes with high sensitivity, making them an ideal platform for the comprehensive study of metabolites.

To gain insight into organismal- or organ-level metabolism and physiology, biological fluids such as plasma, serum, urine, cerebrospinal fluid and tissues are often utilized for metabolomics and lipidomics studies. Maintaining the integrity of the metabolite pool is critical to link metabolite identities and concentrations with biology. The collection and processing of clinical samples require a series of physical and chemical processing steps that expose metabolites to degradation and alteration (e.g., enzymatic or oxidation). Processing time, storage condition, shipping time, anticoagulants, and freeze-thaw cycles, among other variables, could introduce analytical and experimental biases that might introduce significant technical challenges to the rigor of clinical research. It can be challenging, even with comprehensive statistical approaches, to differentiate between systematic bias in sample processing and handling vs. experimental group distinction [17]. Confounding factors introduced during sample collection, handling, and processing must be characterized before initiation of lipidomics or metabolomics measurements to prevent the misinterpretation of results and to enhance accuracy [18].

Several studies have been conducted to study the effect of anticoagulants, time, and temperature on metabolites and lipids in biological specimens. Such studies are performed to develop an optimal procedure for clinical sample collection. For example, the extent of the anticoagulant effect on metabolites depends upon metabolite class, anticoagulant concentration, and anticoagulants type. Anticoagulants have the ability to enhance metabolite ionization, increase matrix effects [19-21], or introduce chemical noise interfering with metabolites quantitation [22]. Given these complexities, it is not surprising that several studies have reported incoherent findings on the effect of additives, 
temperatures and time on biological samples [23-28]. Some metabolites are resistant to degradation over time, depending on storage temperature. Other metabolites are labile and susceptible to degradation even when stored at conventional processing temperatures $\left(4^{\circ} \mathrm{C}\right)$ [29]. The evaluation of possible biases introduced during sample collection, processing, and handling can further guide in experimental design and reduce the effect of the confounding factors on results. Such studies also assist in the development of standard operating procedures (SOP) for the high throughput omics-based studies. Thus, such studies are critical to assess the effect of sample handling artifacts on biological specimens before conducting large-scale studies.

Here we detail a study to assess the effect of storage time, temperature, and anticoagulants (collection tube types) on healthy donors' plasma samples in preparation for subsequent vaccine studies conducted through the NIH-funded Vaccine Treatment and Evaluation Unit (VTEU). We also investigate some of the possible physical conditions that samples may encounter during collection, storage, shipping, and handling from collection sites. The findings from this study will be utilized to guide sample collection and processing workflow not only for metabolomics and lipidomics but also at the systems-level including proteomics and transcriptomics (reported elsewhere).

\section{Materials and Methods}

\subsection{Reagents and Chemicals}

All lipid standards were purchased from Avanti Polar Lipids Inc. (Alabaster, AL, USA). HPLC-grade extraction and LC-MS solvents were purchased from Fisher Scientific (Hampton, NH, USA) and Sigma Aldrich (St. Louis, MO, USA).

\subsection{Lipid Extraction and LC-MS}

A total of seventy plasma samples collected from five healthy donors were obtained from an Emory IRB approved healthy donor protocol and identified as D11, D12, D13, D14, and D15. Plasma samples were collected in two different types of tubes containing di-potassium ethylenediaminetetraacetic acid ( $\mathrm{K}_{2}$ EDTA) or a sodium citrate (Na-citrate)-containing cell preparation tube (BD Vacutainer Systems, NJ, USA), respectively. Donor plasma in each tube type was stored for five different lengths of time $(0 \mathrm{~h}(0 \mathrm{H}), 2 \mathrm{~h}(2 \mathrm{H}), 4 \mathrm{~h}(4 \mathrm{H}), 8 \mathrm{~h}(8 \mathrm{H})$, and $24 \mathrm{~h}(24 \mathrm{H}))$ prior processing. The $\mathrm{K}_{2}$ EDTA-containing plasma samples were stored at $4{ }^{\circ} \mathrm{C}$ or room temperature $\left(22^{\circ} \mathrm{C}\right)$ and the sodium-citrate-containing plasma samples were stored at room temperature (Refer to Figure 1 for detail analytical strategy for metabolomics and lipidomics data). For brevity, the $\mathrm{K}_{2}$ EDTA samples at $4{ }^{\circ} \mathrm{C}, \mathrm{K}_{2}$ EDTA samples at room temperature and sodium-citrate samples at room temperature will be represented as EDTA_4C, EDTA, and CPT respectively.

Lipids were extracted from the seventy healthy donor plasma samples using the Bligh-Dyer method [30], with slight modifications according to the following brief protocol. A 2:1 v/v methanolchloroform mixture $(1.8 \mathrm{~mL})$ was added to $200 \mu \mathrm{L}$ of human plasma and vortexed for $30 \mathrm{~min}$. An additional $1.2 \mathrm{~mL}$ methanol: chloroform mixture $(1: 1 v / v)$ was added to the mixture and vortexed briefly. The organic and aqueous phases were separated by adding $0.5 \mathrm{M}$ sodium chloride solution and centrifuged at $2500 \mathrm{rpm}$ for $10 \mathrm{~min}$. The organic fraction was collected in a clean glass vial and was dried and stored at $-80^{\circ} \mathrm{C}$ until further processing.

Frozen extracts were reconstituted in $100 \mu \mathrm{L}$ of a 1:1 $v / v$ methanol: chloroform mixture and $100 \mu \mathrm{L}$ of internal standard with gentle shaking and brief vortexing. Solvent-only blank solutions were prepared using the reconstituted solvent mixture (methanol: chloroform 1:1 $v / v$ ). Test samples were prepared by diluting LipidoMix 1:100 (Avanti Polar Lipids Inc. Alabaster, AL, USA) in 1:1 v/v methanol:chloroform to observe baseline lipid separation and the response of the instrument before running the samples. Chromatographic separation was performed using an UltiMate ${ }^{\mathrm{TM}} 3000$ Rapid Separation Binary System (Thermo Scientific; Waltham, MA) and a Waters ACQUITY UPLC BEH C18 column $(2.1 \times 50 \mathrm{~mm}, 1.7 \mu \mathrm{m}$ particle size $))$. Lipids classes were separated and eluted using 
binary solvent systems comprised of water: acetonitrile (40:60 v/v; mobile phase A) and isopropanol: acetonitrile (90:10 $v / v$; mobile phase B,) with both phases A and B containing $10 \mathrm{mM}$ ammonium formate and $0.1 \%$ formic acid. The gradient flow parameters of mobile phase B were as follows: $0-1 \mathrm{~min}$ $40 \%-45 \%$, 1.0-1.1 $\min 45 \%-50 \%, 1.1-5.0 \mathrm{~min} 50 \%-55 \%, 5.0-5.1 \mathrm{~min} 55 \%-70 \%, 5.1-8.0 \mathrm{~min} 70 \%-99 \%$, 8.0-8.1 $\mathrm{min} 99 \%-40 \%, 8.1-9.5 \mathrm{~min} 40 \%$. The solvent flow was maintained at $0.4 \mathrm{~mL} / \mathrm{min}$ throughout the LC run. The column temperature was set at $50^{\circ} \mathrm{C}$. Five microliters of sample, from the $200 \mu \mathrm{L}$ reconstituted volume, was injected into LC-MS for data acquisition in data-dependent acquisition mode (DDA) using a Q Exactive HF mass spectrometer (Thermo Fisher; Waltham, MA) equipped with an electrospray ionization (ESI) source, in both positive and negative ion modes. Full and data-dependent acquisition (DDA) scans data were collected at 120,000 and 15,000 resolution, respectively. The mass spectrometer parameters were as follows: AGC target-1.0E5; maximum IT-250 ms; scan range- $m / z$ 100 to 1500 for full scan; AGC target-1.0E5; maximum IT-30 ms; TopN-10; isolation window- $m / z$ 0.4, scan range- $m / z 200$ to 2000, NCE-10, 30, 50; Underfill ratio-1.0\%, charge exclusion-3-8, > 8; dynamic exclusion-15.0 s for DDA scan modes. The instrument was tuned to a mass accuracy of below \pm 3 ppm and separation quality was inspected using lipid extract from the commercially available normal human plasma and Lipidomix (Avanti Polar Lipids, Alabaster, AL) before starting the data acquisition for the experimental samples. The chromatogram (Supplementary Material 5) shows the lipids separation in positive and negative ionization modes.

\subsection{Metabolite Extraction and LC-MS}

Approximately $100 \mu \mathrm{L}$ of 2:1 $v / v$ acetonitrile-water mixture containing internal isotopic mixture was added to the $50 \mu \mathrm{L}$ of thawed plasma sample, as previously described [31,32]. Following mixing and incubation at $4{ }^{\circ} \mathrm{C}$ for $30 \mathrm{~min}$, precipitated proteins were pelleted via centrifugation for $10 \mathrm{~min}$ at the $13,500 \times g$ on a microcentrifuge at $4{ }^{\circ} \mathrm{C}$. Samples were analyzed in triplicate by LC-MS (ThermoScientific High Field (HF) Q Exactive coupled to a Dionex Ultimate 3000 LC system; mass-to-charge ratio $(\mathrm{m} / \mathrm{z})$ range from 85 to 1250 Daltons at $120 \mathrm{~K}$ resolution) with a $10 \mu \mathrm{L}$ injection volume via electrospray ionization. Analyte separation for HILIC was accomplished by a $2.1 \mathrm{~mm} \times 50 \mathrm{~mm} \times 2.5 \mu \mathrm{m}$ Waters XBridge BEH Amide XP HILIC and an eluent gradient $(\mathrm{A}=2 \%$ formic acid, $\mathrm{B}=$ water, $\mathrm{C}=$ acetonitrile) consisting of an initial $1.5 \mathrm{~min}$ period of $2.5 \% \mathrm{~A}, 22.5 \% \mathrm{~B}, 75 \% \mathrm{C}$ followed by a linear increase to $2.5 \%$ $\mathrm{A}, 77.5 \% \mathrm{~B}, 20 \% \mathrm{C}$ at $4 \mathrm{~min}$ and a final hold of $1 \mathrm{~min}$. RPC separation was by $2.1 \mathrm{~mm} \times 50 \mathrm{~mm} \times 3$ $\mu \mathrm{m}$ endcapped $\mathrm{C}_{18}$ column (Higgins) using an eluent gradient $(\mathrm{A}=2 \% 5 \mathrm{mM}$ ammonium acetate, $\mathrm{B}=$ water, $\mathrm{C}=$ acetonitrile) consisting of an initial $2 \mathrm{~min}$ period of $5 \% \mathrm{~A}, 90 \% \mathrm{~B}, 5 \% \mathrm{C}$, followed by a linear increase to $5 \% \mathrm{~A}, 0 \% \mathrm{~B}, 95 \% \mathrm{C}$ at $6 \mathrm{~min}$ and held for the remaining $4 \mathrm{~min}$. For both methods, the mobile phase flow rate was held at $0.35 \mathrm{~mL} / \mathrm{min}$ for the first $1.5 \mathrm{~min}$, increased to $0.5 \mathrm{~mL} / \mathrm{min}$ and held for the final $4 \mathrm{~min}$. The high-resolution mass spectrometer was operated at 120,000 resolution and mass-to-charge ratio $(\mathrm{m} / \mathrm{z})$ range $85-1275$. Probe temperature, capillary temperature, sweep gas and S-Lens RF levels were maintained at $200{ }^{\circ} \mathrm{C}, 300^{\circ} \mathrm{C}, 1$ arbitrary unit (AU), and 45, respectively, for both polarities. Additional source tune settings were optimized for sensitivity using a standard mixture, positive tune settings for sheath gas, auxiliary gas, sweep gas and spray voltage setting were 45 AU, $25 \mathrm{AU}$ and $3.5 \mathrm{kV}$, respectively; negative settings were $30 \mathrm{AU}, 5 \mathrm{AU}$ and $-3.0 \mathrm{kV}$. Maximum C-trap injection times of 100 milliseconds and automatic gain control target of $1 \times 10^{6}$ for both polarities. During untargeted data acquisition, no exclusion or inclusion masses were selected, and data were acquired in MS1 mode only. The chromatogram (Supplementary Material 6) shows the metabolites separation in positive and negative ionization modes.

\subsection{Data Preprocessing and Analysis}

The lipidomics raw data were processed using MZmine 2.31 [33,34]. All mass spectral data with a signal-to-noise ratio $>10$ and mass intensity $>1.0 \mathrm{E} 4$ were further processed according to the following steps. Briefly, processing includes mass detection and chromatogram building, chromatogram deconvolution, deisotoping, alignment, gap filling, and filtering. The final preprocessing of raw data 
contained information on mass, retention time, lipid species, and intensity. The processed features were annotated using exact mass information within \pm 5 ppm mass accuracy using the LIPID MAPS online server [35]. Further, lipid species were confirmed by the utilizing DDA data in LipidMatch 2017_5_3 version [36] and LipidSearch 4.1.28 (Thermo Fisher Scientific Inc., San Jose, CA, USA). Finally, the identified lipid species along with exact mass-based annotated features and unknown features were statistically analyzed to investigate the change in lipid profiles among different donor samples due to anticoagulant use and/or collection conditions. All the lipids identified based on exact mass are represented in the format "LIPIDMAPS_number" and the unknowns are labeled as "Unknown_number" for brevity. The LIPID MAPS nomenclature system [37] is used to name the lipids reported in this study and identified lipids are abbreviated as reported by the identification software [36]. For lipidomics, a total of 3,881 features in positive mode and 803 features in negative mode were extracted after preprocessing the raw mass spectral data. The identified features covered diverse lipid classes, such as lysophospholipids, phospholipids, cholesteryl esters (CEs), triacylglycerols (TGs), diacylglycerols (DGs), sphingolipids, and acylcarnitines (AcCas). The lipidomics data were quantile normalized, generalized log transformed and Pareto scaled whereas the metabolomics data were quantile normalized, $\log 2$ transformed and auto-scaled before performing downstream statistical analyses.

The metabolomics raw data were converted to open format (netCDF) using Xcalibur software (ThermoScientific, Waltham, MA). Data were extracted using apLCMS [38] as $\mathrm{m} / \mathrm{z}$ features and batch-corrected with xMSanalyzer [39], where an $m / z$ feature is defined as an accurate mass $m / z$ with associated retention time (RT; in seconds) and intensity. Quantification results for each of the samples and external controls were recorded as LC-MS peak area. The data was tentatively annotated by xMSannotator [40]. The lipidomics and metabolomics preprocessed data were normalized and statistically treated on Metaboanalyst 4.0 [41,42]. From the metabolomics data, a total 7635 and 8519 features were extracted from positive and negative ionization modes, respectively, among which 178 positive mode and 126 negative mode features were annotated based on exact mass within \pm 5 ppm mass accuracy. All identified and non-identified features were considered for further analysis using univariate and multivariate approaches to study the metabolic profile difference among different time points and anti-coagulants used. The identified lipid data in positive and negative ionization modes were normalized and statistically analyzed to infer the differences in lipid profiles between the sample groups. The metabolomics and lipidomics data were analyzed by using one-way analysis of variance (ANOVA) followed by post-hoc analysis using Fisher's Least Significant Difference (LSD) test. Principal component analysis (PCA) was performed to study sample clustering and outliers.

\section{Results}

Seventy plasma samples from five different healthy donors were grouped and sub-grouped based on anticoagulant type and storage time for statistical analysis of the preprocessed mass spectral features.

A detailed scheme of the analytical strategies is presented in Figure 1. The statistical analyses were performed by two different strategies-donor-matched and donor-unmatched for positive and negative mode data-and a similar analytical strategy was followed for the metabolomics data. In the donor-matched strategy, each donor was analyzed separately by grouping storage time and anticoagulant used. Thus, statistical treatment was undertaken for five donors separately to determine the effect of storage time and anticoagulants in the plasma lipid profile. The donor-unmatched samples were analyzed to study the effect of storage time and anticoagulants collectively, including all the donors under study. 


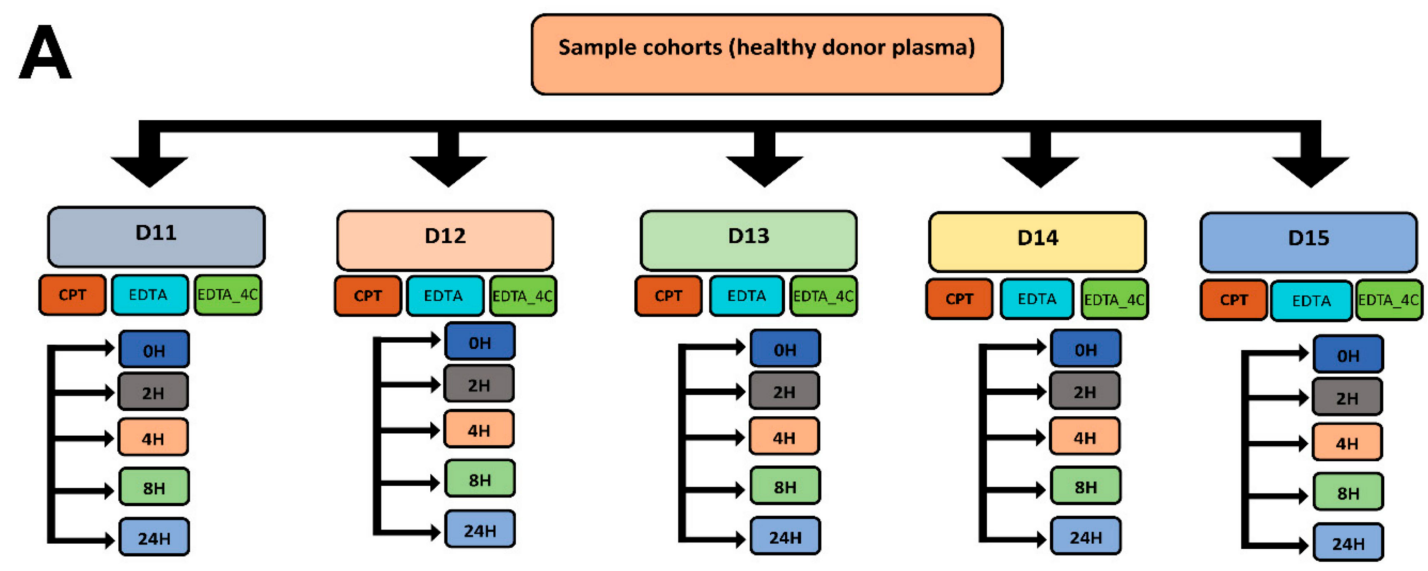

B

Sample cohorts (healthy donor plasma)
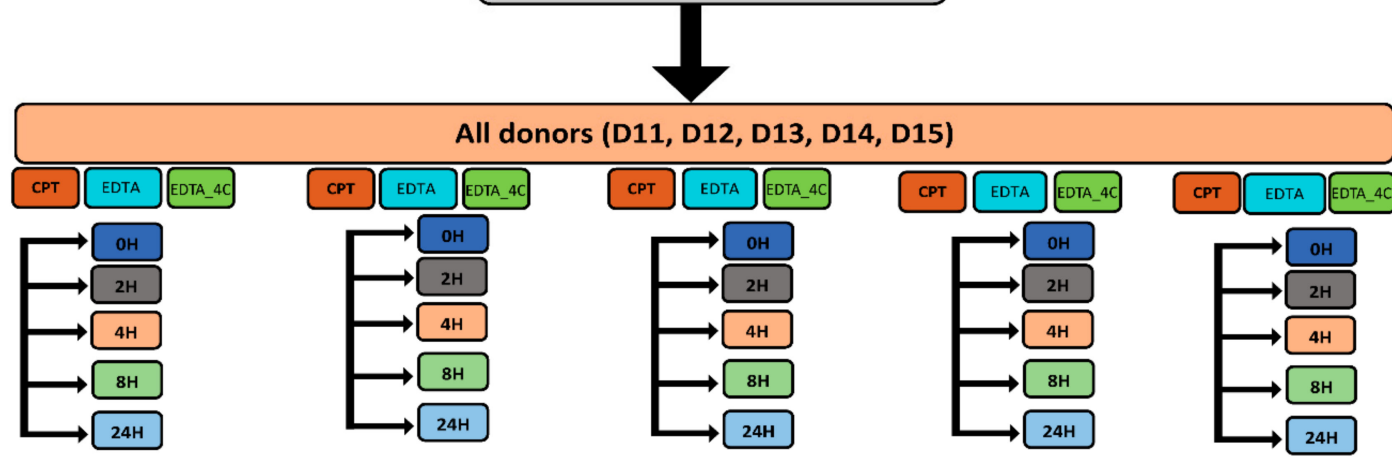

Figure 1. Statistical analysis strategies for untargeted lipidomics. (A) donor-matched strategy and (B) donor-unmatched strategy. The study comprises five donors (D11, D12, D13, D14, and D15), two different anticoagulants sodium citrate and potassium ethylenediaminetetraacetic acid represented as CPT and EDTA respectively, two different temperatures $\left(4^{\circ} \mathrm{C}\right.$ and room temperature $)$ and five different storage times before processing $(0 \mathrm{H}, 2 \mathrm{H}, 4 \mathrm{H}, 8 \mathrm{H}$, and $24 \mathrm{H})$. The $0 \mathrm{H}$ EDTA samples represent the baseline for both EDTA containing samples at $4{ }^{\circ} \mathrm{C}$ and room temperature.

Principal component analysis (PCA) was performed for the donor-unmatched samples by grouping the samples according to storage time and the anticoagulants used. Samples did not group based on storage time in the PCA, indicating minimal or no contribution of storage time related variance on sample clustering. Rather, the variance between donors contributed far greater to the PCA than storage time (Figure 2A). The One-way Analysis of Variance (ANOVA) with Fisher's LSD test corroborated the PCA observations that no lipid species were significantly different across different storage times using a false discovery rate (FDR) of 0.05 except for one unknown feature (Figure 2C). Similar results were obtained for negative mode data. The PCA analysis of donor-unmatched samples for positive mode data based on anticoagulant grouping did not show clustering based on anticoagulant rather the clustering was dominantly based on donors' lipid profile (Figure 2B). Nonetheless, the One-way ANOVA analysis with post-hoc Fisher's LSD test showed 347 features significantly different between anticoagulants (Figure 2D, Supplementary Material 1), among which 22 were MS/MS confirmed lipids, 138 were exact mass-based annotated lipids, and 187 were unknown features. Similarly, the ANOVA analysis with Fisher's LSD test of negative mode analysis showed 78 features to be significantly different at an FDR of 0.05. Among these six features were MS/MS confirmed lipids, 20 were exact mass-based lipid annotations and 52 were unidentified features (refer to Supplementary Material 2). Of the MS/MS confirmed positive mode lipids, most were glycerophospholipids with phosphatidylethanolamines (PEs) as the dominant class. The other confirmed lipids belonged to cholesteryl esters (CEs), acylcarnitine 
(AcCa), triacylglycerols (TGs), and coenzyme Q9. All MS/MS confirmed lipids were found to be higher in EDTA tubes except $\mathrm{AcCa}(18: 2)[\mathrm{M}+\mathrm{H}]$ and oxTG(16:0_18:1_18:3(OO)) $\left[\mathrm{M}+\mathrm{NH}_{4}\right]$ which were found to be higher in CPT tubes. Of the $6 \mathrm{MS} / \mathrm{MS}$ confirmed negative mode lipids, three were PEs, two were sphingomyelins (SMs), and one was phosphatidylcholine (PC).

A

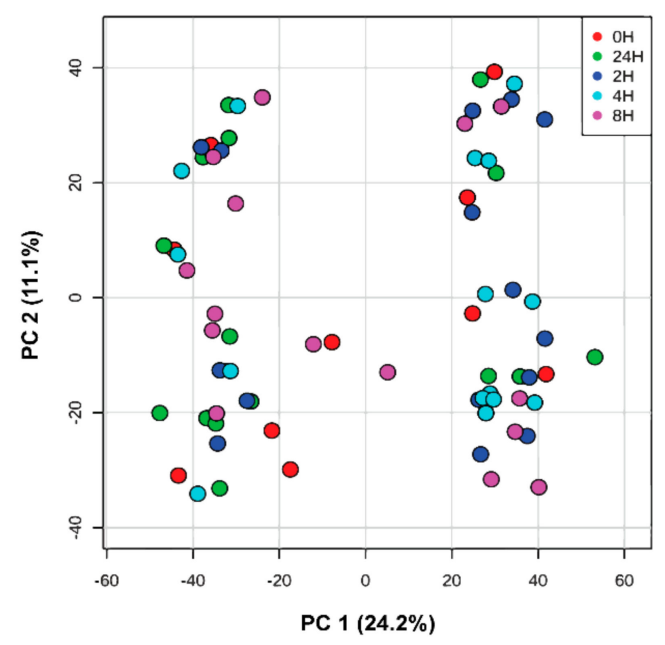

B

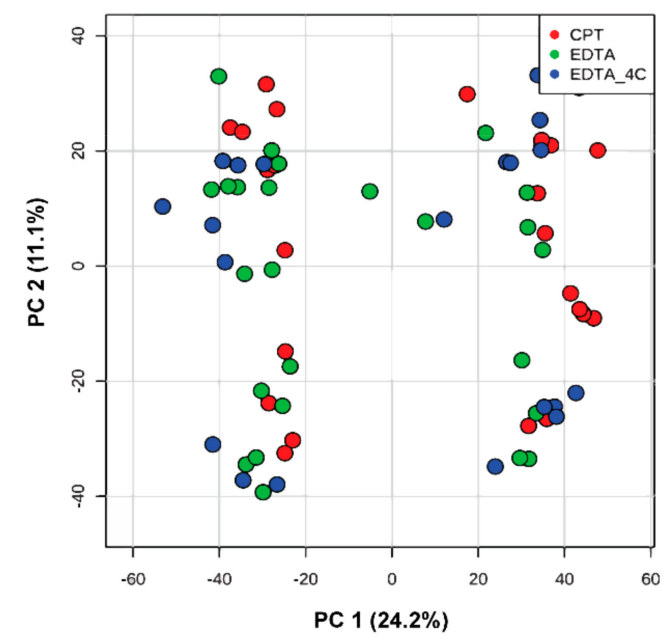

C

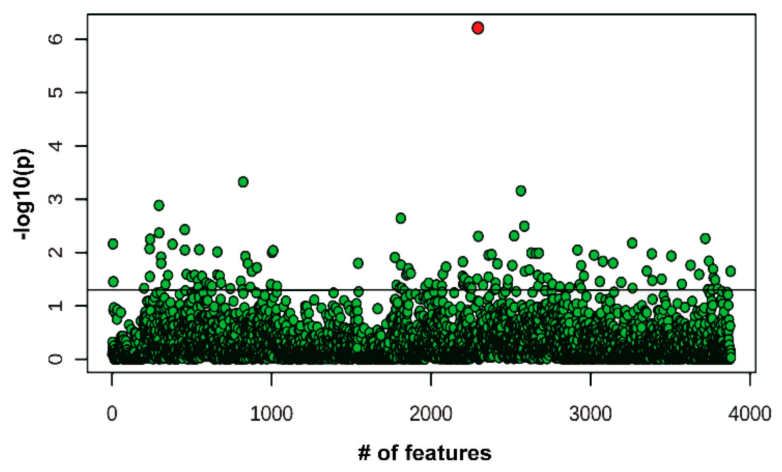

D

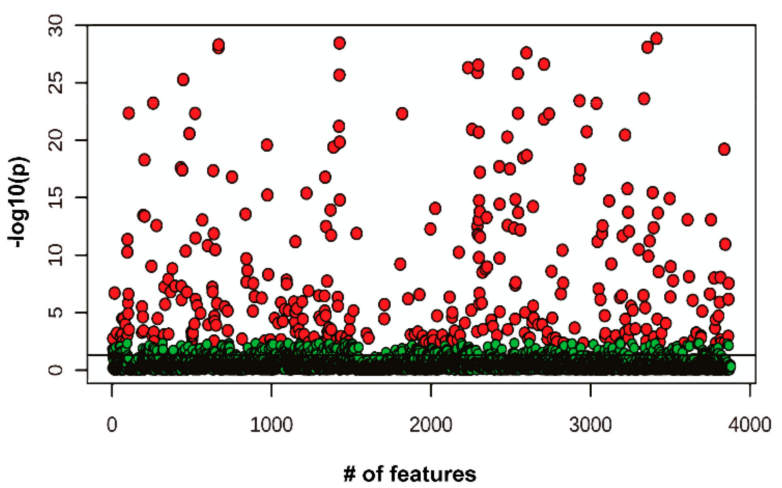

Figure 2. Principal component analysis in donor-unmatched samples from lipidomics data acquired in positive ionization mode. Samples are grouped by (A) storage time and (B) anticoagulants used. Analysis of variance with Fisher's Least Significant Difference (LSD) test at adjusted p-value at 0.05 grouped by (C) storage time (red dot show $p$-value $<0.05$ ) and (D) anticoagulants (red dots show $p$-value $<0.05$ ). Note: The $Y$-axis scale of scatter plot is automatically adjusted by Metaboanalyst based on the range of $-\log 10(\mathrm{p})$. The line on the scatter plot demarcates the $-\log 10(0.05)$ value on $Y$-axis.

Further analyses were performed with donor-matched groups to study the effect of anticoagulant and the time of storage. In a donor-matched strategy using positive mode data, PCA grouped samples based on anticoagulant, CPT vs. EDTA/EDTA_4C, indicating anticoagulant is driving differential lipid profiles (Figure 3). Further investigation of differentially abundant lipids was performed by one-way ANOVA in donor-matched samples grouped by anticoagulants used. Among five donor-matched groups, all groups showed a significant effect of anticoagulants (Figure 4, Supplementary Material 2 and 
3) in both ionization modes, with the exception of D14. All significant MS/MS confirmed positive and negative mode lipids in D11 were found to be higher in EDTA tubes with PE being the dominant lipid class. Other lipids include DG(18:0_18:1) $\left[\mathrm{M}+\mathrm{NH}_{4}\right]$ and PS(18:0_20:4) $[\mathrm{M}+\mathrm{H}]$ in the positive mode. Similar results were observed in the D12 positive mode data. All significant confirmed lipids were higher in EDTA tubes and all of them were PEs except PS(18:0_20:4) [M + H]. The positive mode D13 data showed the maximum number of confirmed lipids that were significantly different between tube types including phospholipids, AcCa, sphingolipids, and TGs. Again, PE was the most differentially abundant lipid class. All the lipids were higher in EDTA containing tubes except PE(36:0) $[\mathrm{M}+\mathrm{H}]$, OxTG(16:0_18:1_18:3(OO)) [M + NH4], PG(17:0_17:0) [M + H]. To note, PG (17:0_17:0) [M + H] was one of the internal standards spiked into the samples. All the differentially abundant lipids in the D13 negative mode data were phospholipids (PC and PE) and were more abundant in EDTA containing tubes (Supplementary Material 2). Donor D15 had all the significant confirmed lipids higher in EDTA containing tubes except OxTG(16:0_18:1_18:3(OO))[M + $\left.\mathrm{NH}_{4}\right]$ which was more abundant in the CPT tube. The differentially abundant lipids in D15 EDTA tubes include phospholipids (PE, PI, and PS), CE, and ceramides. No confirmed lipid was found to be differentially abundant in D15 negative mode data though 28 unknown features were found to be significantly different between anticoagulants (Supplementary Material 2). The ANOVA analysis with a Fisher LSD test of donor-matched samples grouped by storage time did not show any difference in lipid profile for positive mode data except for donor D12 where 5 lipids showed significant difference at FDR 0.05 out of which 3 lipids were identified only by exact mass based. Similar analysis with negative mode lipidomics data showed a significant effect of storage time on donors D11 and D12 with 110 (6 MS/MS confirmed) and 262 (36 MS/MS confirmed) differentially abundant lipids, respectively (FDR 0.05). Donors D13 and D14 did not show a significant effect whereas D15 showed one lipid, PE(16:0_22:6) [M - H] significantly different at FDR 0.05 (Supplementary Material 4). The effect of storage time on lipids was prominent in negative mode data when analyzed by the donor-matched strategy. Figure 5 shows the overall lipid profile difference within donors in negative ionization mode grouped by storage time (Figure 5).

Similar analyses were performed for positive and negative ionization mode metabolomics data. All the statistical analyses were performed by using Metaboanalyst 4.0 [43]. Missing imputation was performed by calculating half of the minimum positive values in the original data. The data were quantile normalized, $\log 2$ transformed, and auto-scaled. A principal component analysis was performed followed by ANOVA to detect differentially abundant metabolites due to the effect of storage time and anticoagulants on plasma samples.

For the donor-unmatched strategy, the PCA on time-grouped data showed two clusters of samples based on the anticoagulant contrary to storage time (Figure 6A). Further, the ANOVA with post hoc Fisher LSD test showed three significantly different unknown metabolites for samples stored at different time points in positive mode data (Figure 6C). For the donor-unmatched storage-time grouped negative mode data, no significantly different lipids were observed. Similarly, the anticoagulant-grouped samples showed PCA clustering based on anticoagulant type (Figure 6B) and the ANOVA with post hoc Fisher LSD analyses showed 2867 (Figure 6D, Supplementary Material 1) and 2341 features (Supplementary Material 2) to be differentially abundant in positive and negative mode data, respectively. Differentially abundant known metabolites (at FDR 0.05; 52 known metabolites in positive and 21 known metabolites in negative mode) spanned multiple biochemical pathways. Most of the differentially abundant metabolites were higher in EDTA-containing plasma samples whereas fewer metabolites were enriched in citrate-containing plasma samples. 

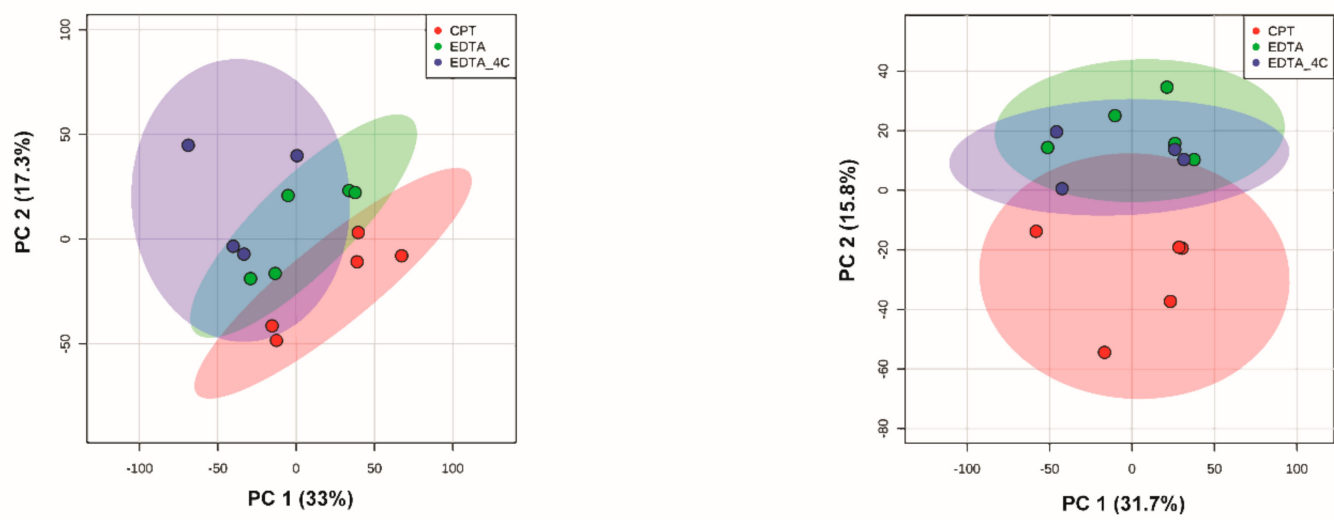

D13

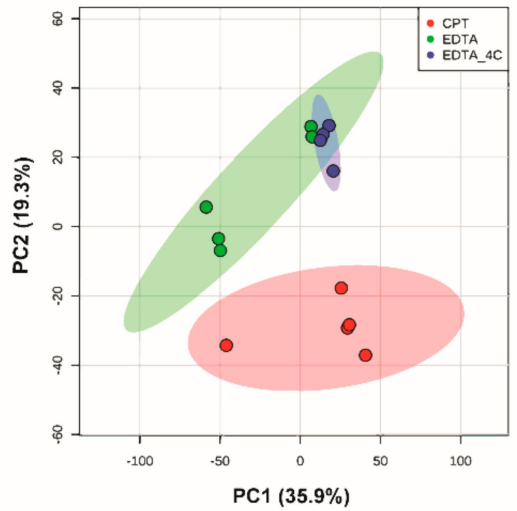

D14
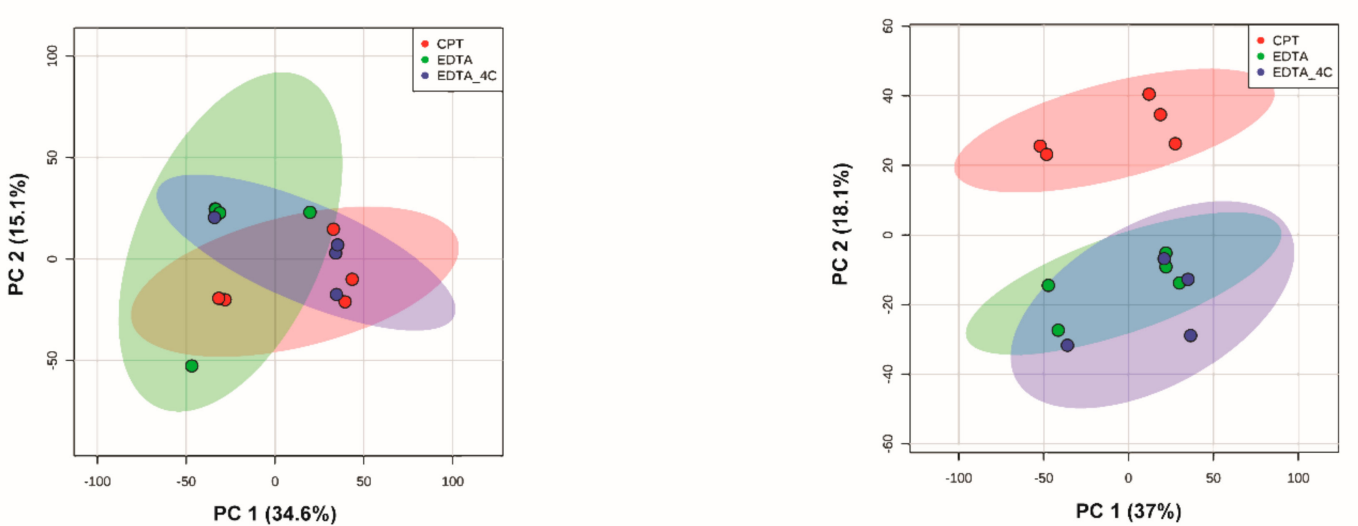

PC $1(37 \%)$

Figure 3. Principal component analysis among donor-matched samples grouped by anticoagulants used for positive mode lipidomics data. Principal component analysis (PCA) showed differences in lipids between CPT and EDTA preservatives. The colored ellipses represent the $95 \%$ confidence interval. 
A

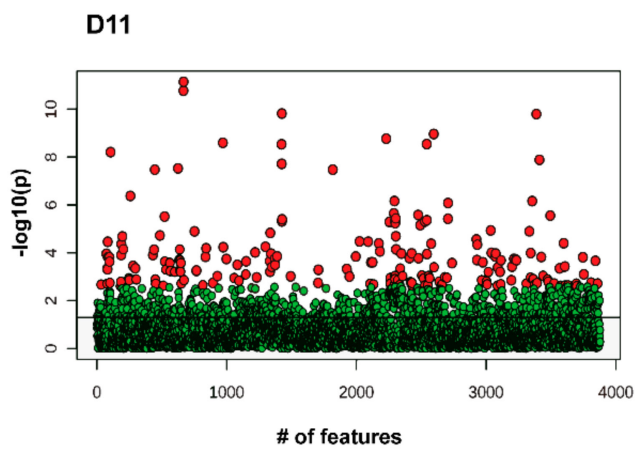

D12

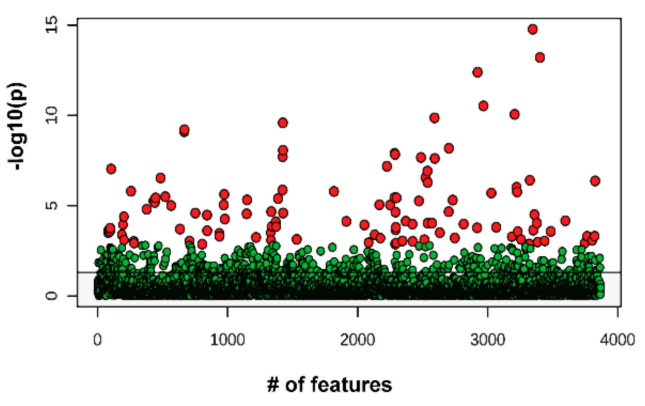

D13

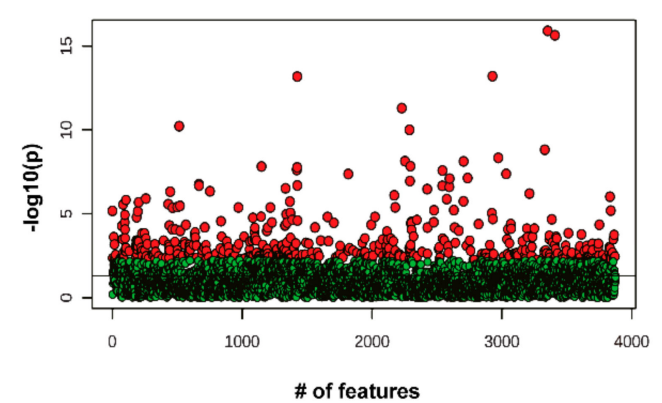

D15

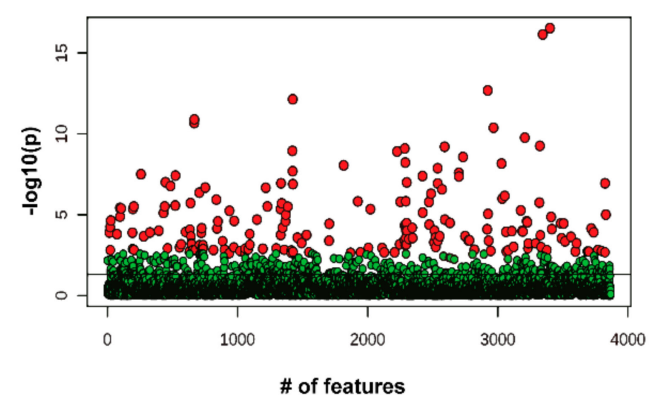

B
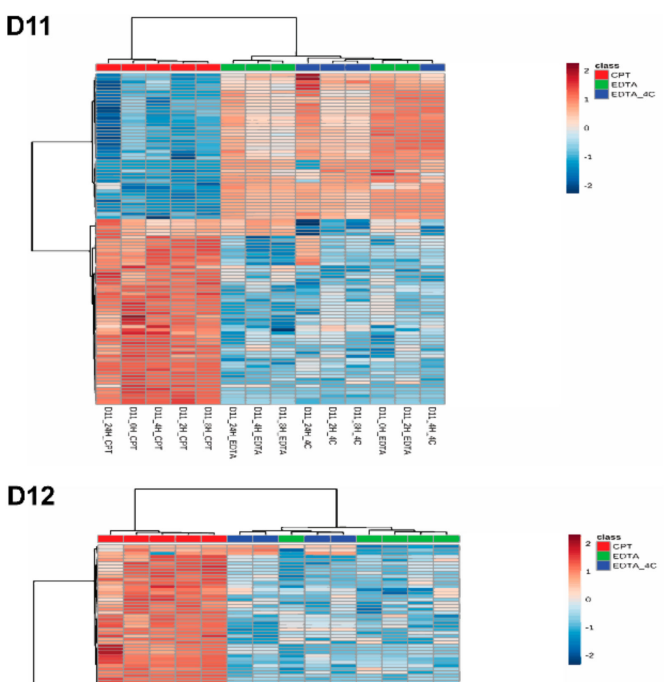

:

T.

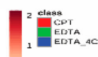

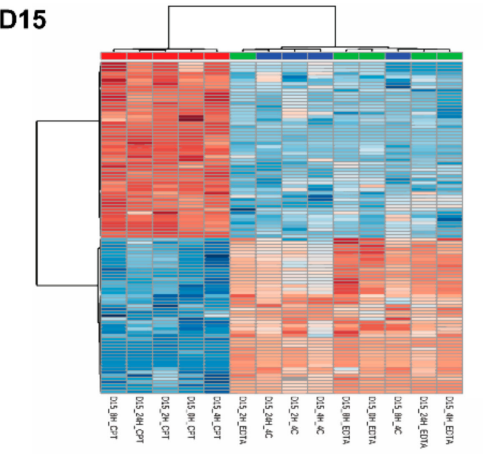

Figure 4. One-way ANOVA analysis of donor-matched lipidomics data. (A) Scatterplot showing One-way analysis of variance among donor-matched samples grouped by anticoagulants (red dots show $p$-value $<0.05$ ). (B) Two-way hierarchical clustering analysis using Euclidean distance and ward.D clustering algorithm among donor-matched samples grouped by anticoagulants. The heatmap shows the top 100 lipid species that are different between CPT and EDTA containing tubes. Note: The $Y$-axis scale of scatter plot is automatically adjusted by Metaboanalyst based on the range of $-\log 10(\mathrm{p})$. The line on the scatter plot demarcates the $-\log 10(0.05)$ value on $Y$-axis. 
D11

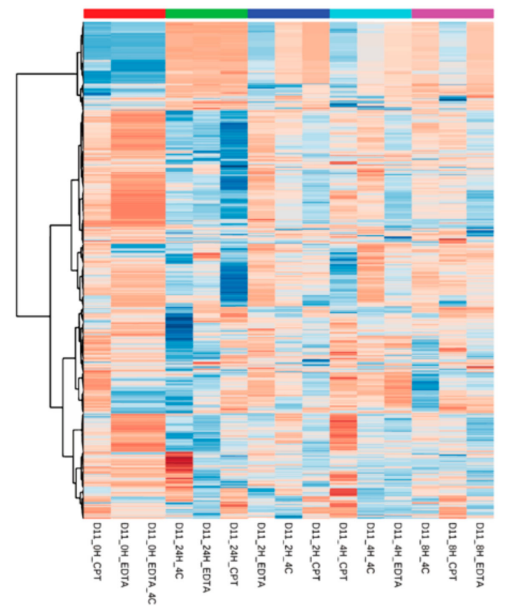

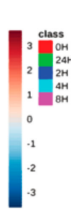

D12

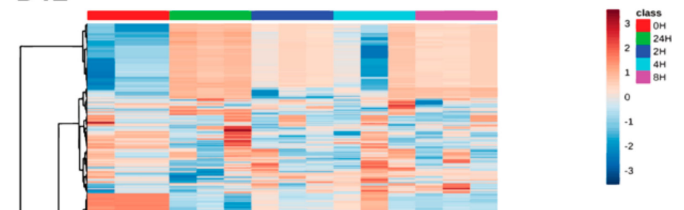

D13

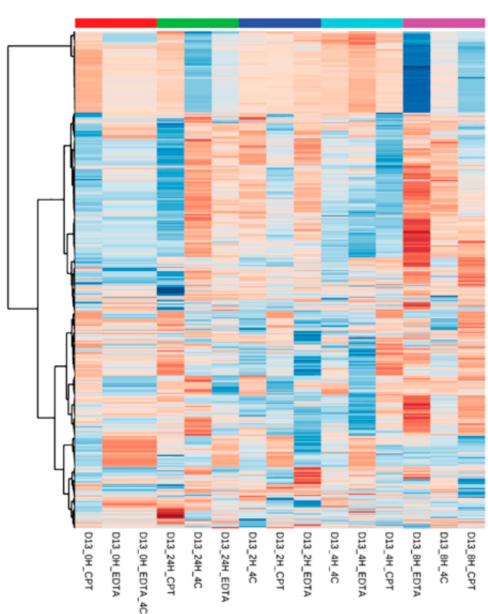

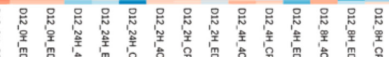

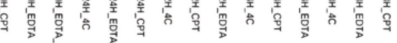

D14

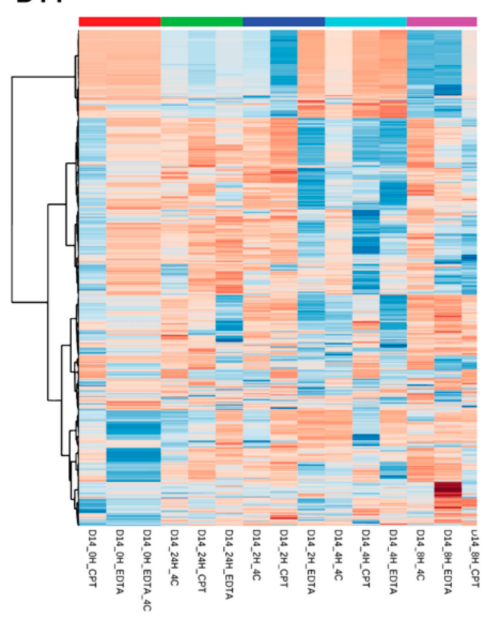

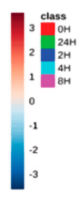

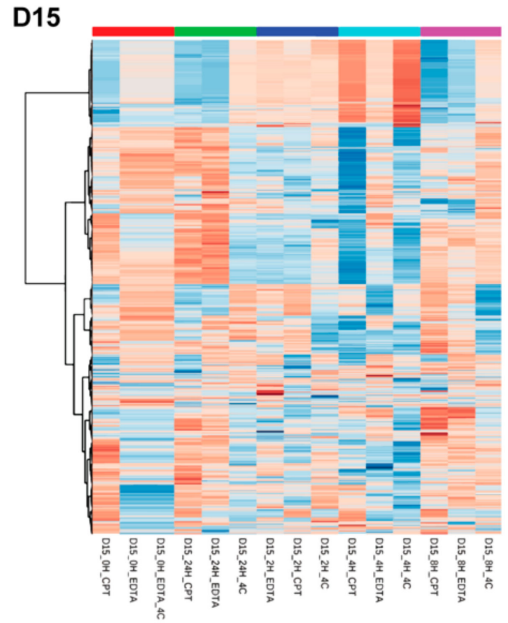

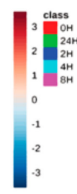

Figure 5. Two-way hierarchical clustering analysis using Euclidean distance and ward.D clustering algorithm among donor-matched samples grouped by storage time. The heatmap shows overall lipid profile differences in negative ionization mode grouped by storage time in donor-matched samples. 
A

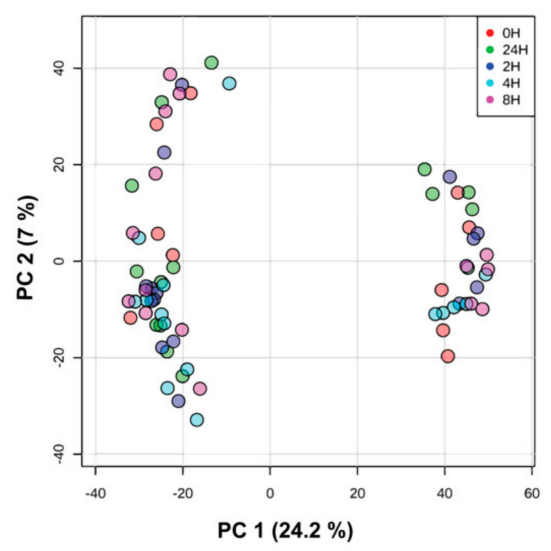

B

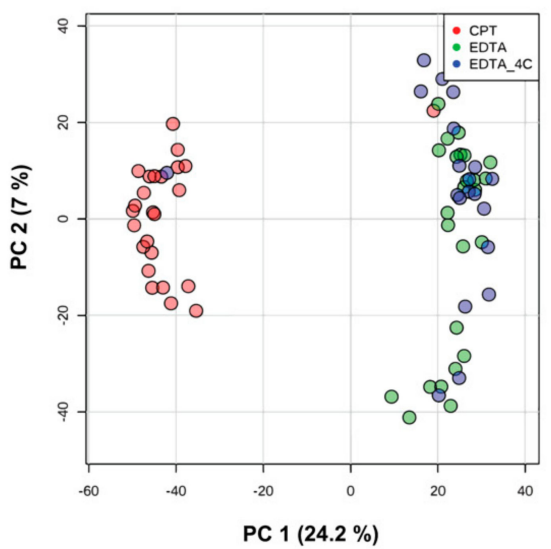

C

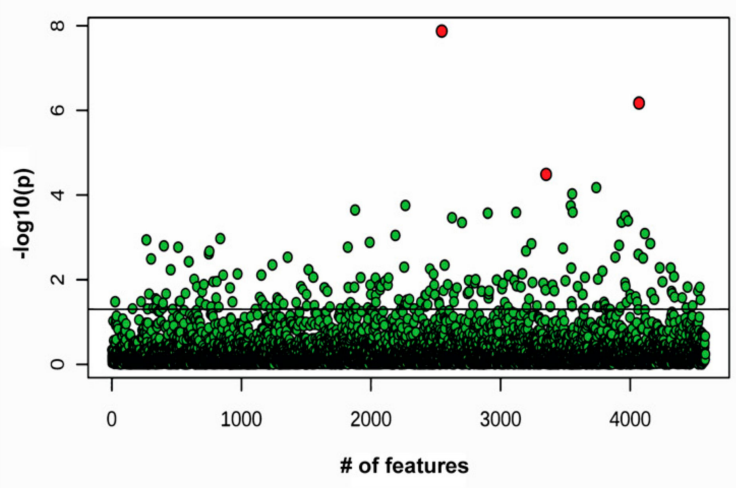

D

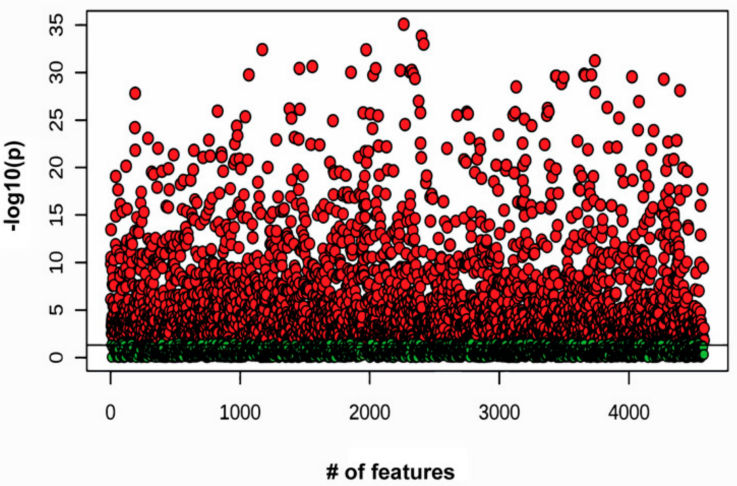

Figure 6. Principal component analysis in donor-unmatched samples from metabolomics data acquired in positive ionization mode. Samples are grouped by (A) storage time and (B) anticoagulants used. Analysis of variance with Fisher's LSD test at adjusted p-value at 0.05 grouped by $(\mathbf{C})$ storage time and (D) anticoagulants (red dots show $p$-value $<0.05$ ). Note: The $Y$-axis scale of scatter plot is automatically adjusted by Metaboanalyst based on the range of $-\log 10(\mathrm{p})$. The line on the scatter plot demarcates the $-\log 10(0.05)$ value on $Y$-axis.

The donor-matched analysis was performed by grouping samples according to storage time and anticoagulants. For each donor, PCA and ANOVA with Fisher LSD analyses were performed to observe the effect of storage time and anticoagulants. PCA showed clustering of samples based on anticoagulants rather than times of storage (Figure 7). Very few metabolites were differently abundant between different storage times at FDR 0.05. The donors D11, D12, D13, D14, and D15 showed four, one, zero, six, and one unknown features in positive mode and four, 55, seven, five, and nine unknown features in negative mode to be differentially abundant, respectively, at FDR 0.05 (Supplementary Material 4). Figure 8 shows the heatmap for donor-matched storage time analysis result for negative mode metabolomics data. One way ANOVA with post hoc analysis at FDR 0.05 showed an array of metabolites to be differentially abundant between CPT and EDTA-containing samples (Figure 9). The donors D11 and D12 showed 1518 (31 identified) and 1055 (19 identified) features in positive (Supplementary Material 3) and 1390 (11 identified) and 1033 (eight identified) (Supplementary Material 2) features in negative modes respectively, different between CPT- and EDTA-containing tubes. Similarly, the donors D13, D14 and D15 showed 1463 (22 identified), 1917 (31 identified) and 1403 (27 identified) 
metabolic features significantly different between anticoagulants at FDR $<0.05$ (refer to the Figure 9 and Supplementary Material 3 for the significantly different features observed in the metabolomics data). The negative mode metabolomics data showed 1361 (14 identified), 1746 (11 identified) and 1344 (10 identified) significantly different features in D13, D14 and D15 (Supplementary Material 2) donors at FDR $<0.05$. Taken together, the lipid profile is affected predominantly by an anticoagulant type followed by minor contributions from storage time. It has also been observed that the storage time affects the lipid and metabolites profile significantly in donor-matched samples however the effect is nullified in the donor-unmatched analysis that might potentially explain the contribution of donor's lipid or metabolite profiles in variation. Donor lipid profiles also contribute to the variance as observed in PCA analysis (Figure 2A,B) whereas the anticoagulant effect is the main determinant of variance in the metabolomics data (Figure 5A,B).
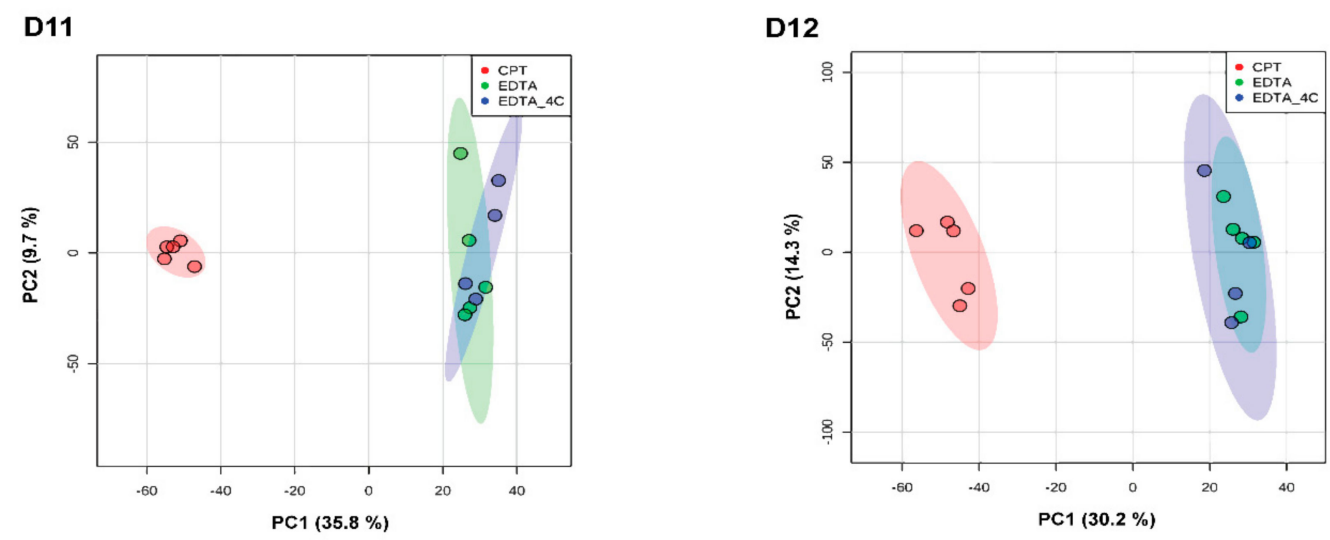

D13
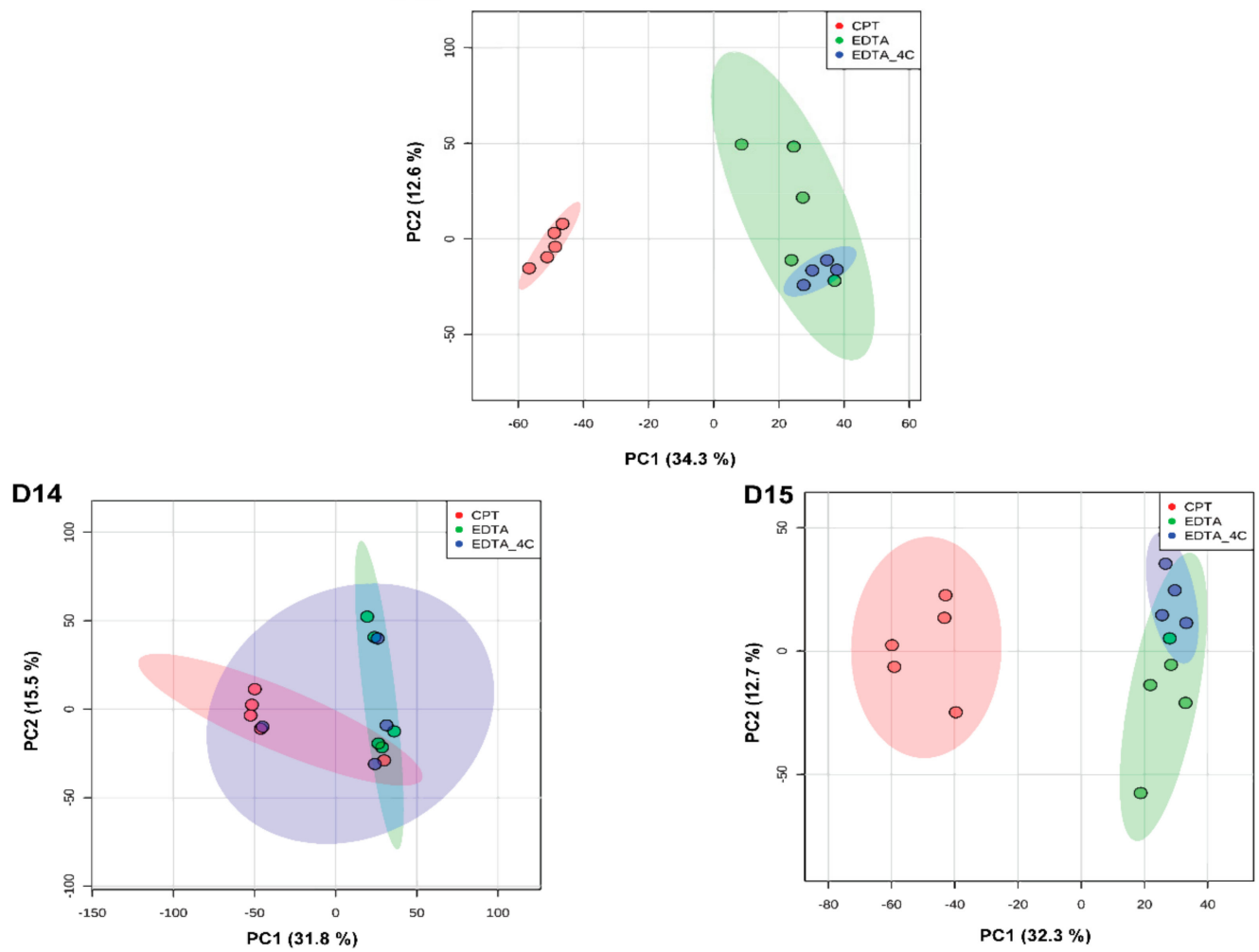

Figure 7. Principal component analysis among donor-matched samples grouped by anticoagulants for metabolomics data acquired in positive ionization mode. The PCA analyses showed differences in lipid profiles between CPT and EDTA. The colored ellipse represents the $95 \%$ confidence interval. 

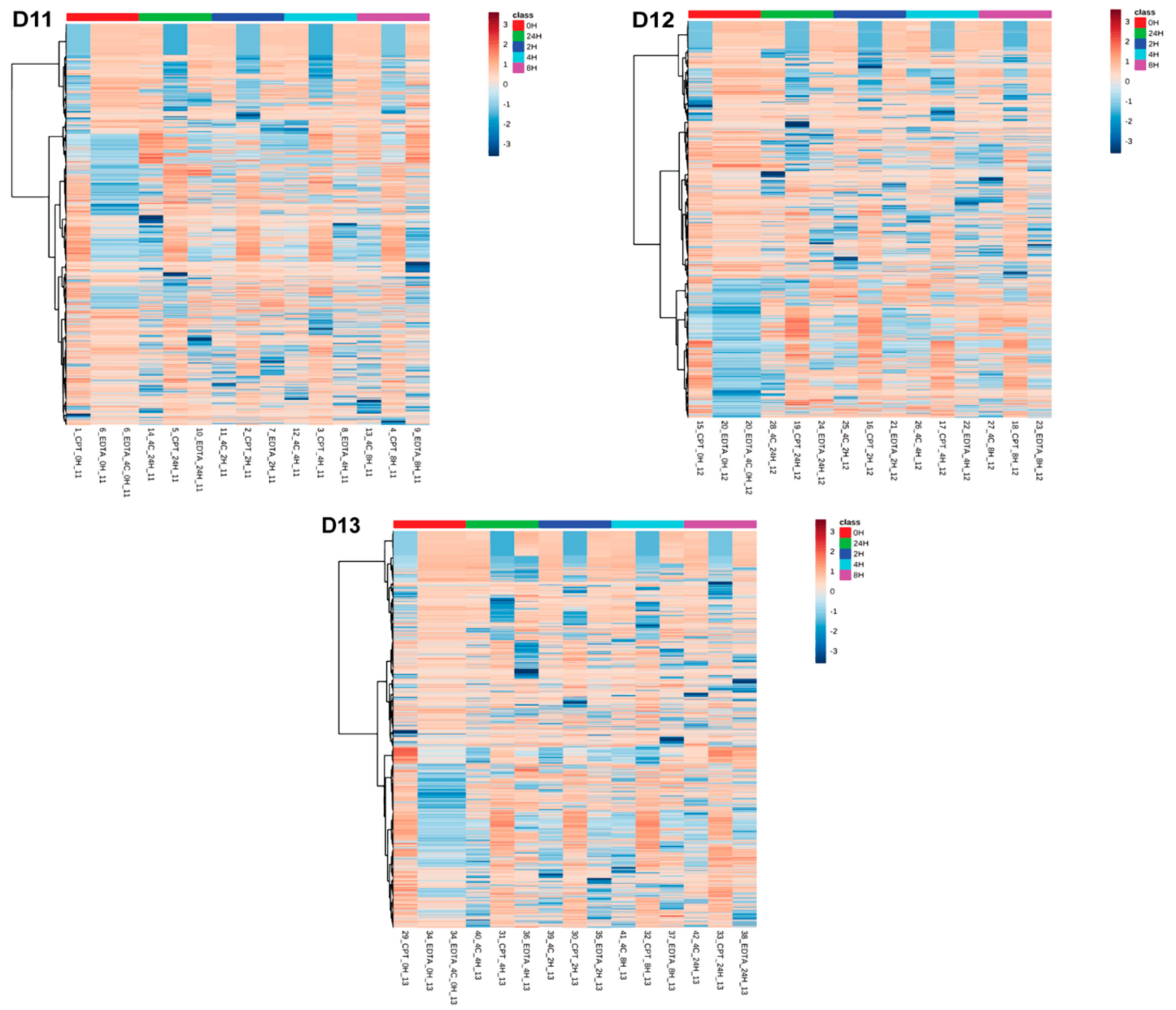

D14

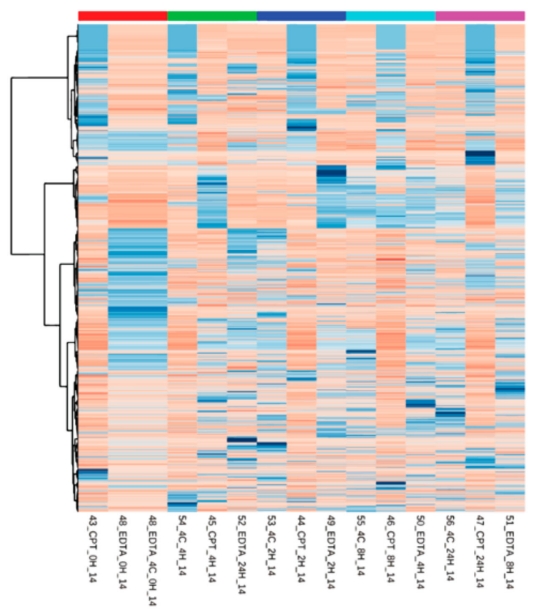

D15

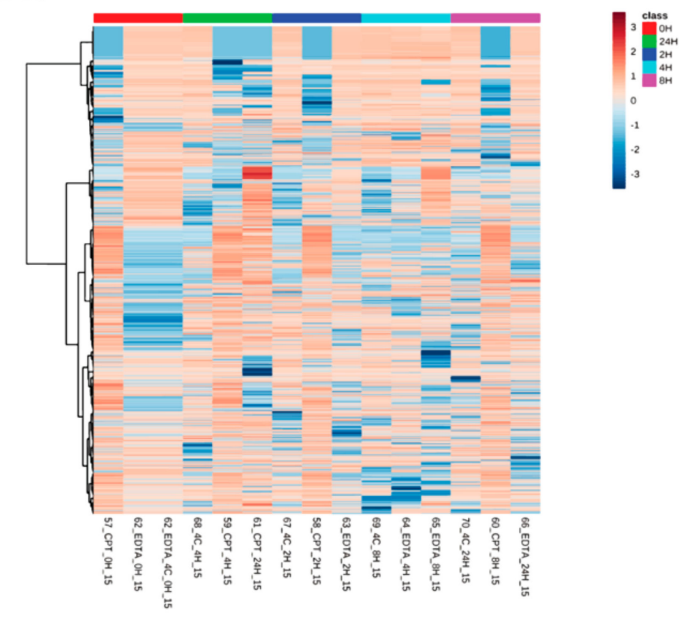

Figure 8. Two-way hierarchical clustering analysis using Euclidean distance and ward.D clustering algorithm among donor-matched samples grouped by storage time. The heatmap shows overall metabolite profile differences in negative ionization mode grouped by storage time in donor-matched samples. 
D11

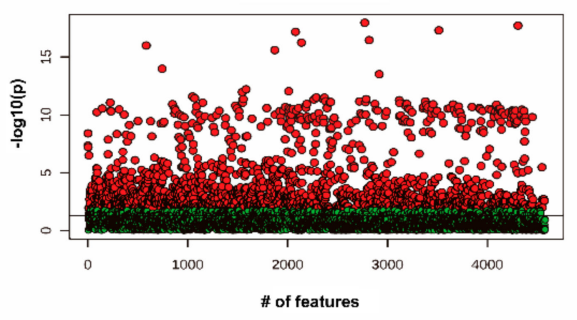

D12

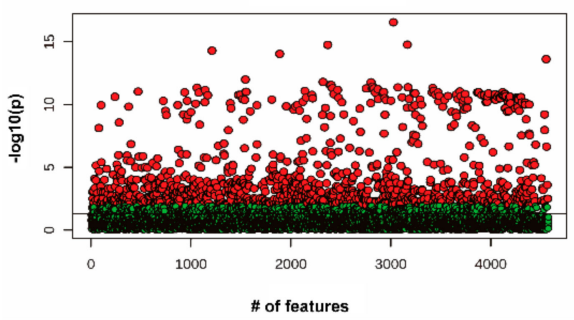

D13

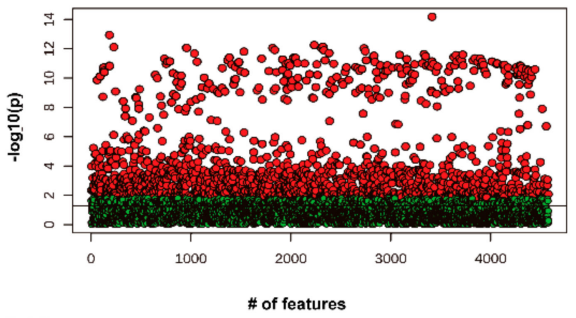

D15

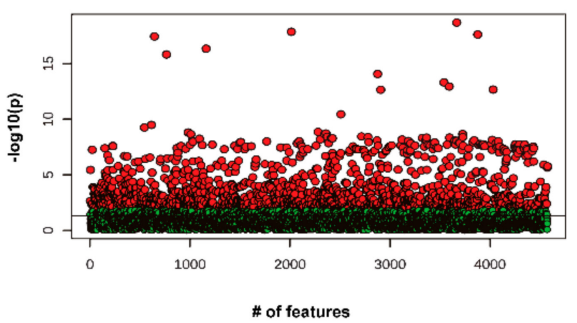

D11
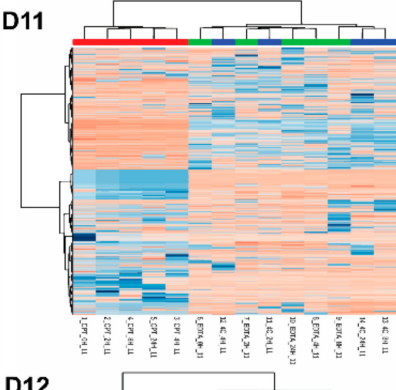

0
$\vdots$

D12
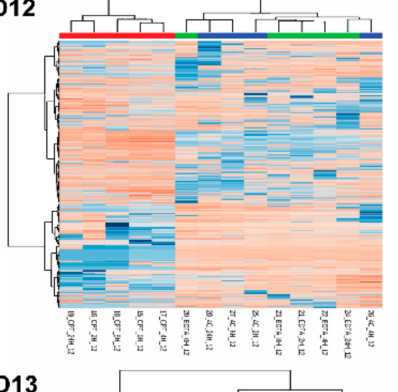

D13

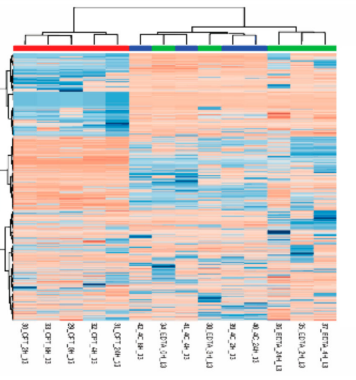

:<smiles>[N+]=[I+]</smiles>

D15

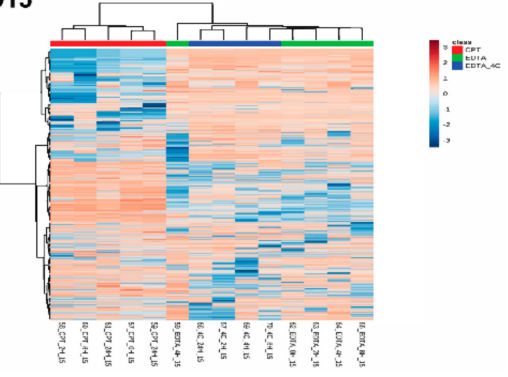

Figure 9. One-way ANOVA analysis of donor-matched metabolomics data. (A) Scatterplot showing One-way analysis of variance among donor-matched samples grouped by anticoagulants (red dots show metabolites with $p$-value < 0.05), (B) Two-way hierarchical clustering analysis using Euclidean distance and ward.D clustering algorithm among donor-matched samples grouped by anticoagulants. The heatmap shows overall features from metabolomics data in positive ionization mode that are different between CPT and EDTA containing tubes. Note: The $Y$-axis scale of scatter plot is automatically adjusted by Metaboanalyst based on the range of $-\log 10(\mathrm{p})$. The line on the scatter plot demarcates the $-\log 10(0.05)$ value on $Y$-axis.

\section{Discussion}

Different physical and chemical conditions are encountered during clinical sample collection, handling, processing and storage which may affect lipid and metabolite composition and abundance in a manner unrelated to the physiology or pathophysiology under study. These sample handling perturbations have the potential to confound attempts to identify biologically meaningful observations; therefore, the source and magnitude of these non-biological effects must be identified prior launching a mass spectrometry based 'omics clinical study. Table 1 summarizes the findings from the previous studies on the effect of different physical and chemical conditions in various biological samples. 
This study evaluated sample handling bias on the metabolome and lipidome of healthy donors prior to launching VTEU vaccine studies conducted in locations that may generate inconsistent sample handling. This is a common issue since sample processing and analysis are usually performed at locations geographically distinct from collection sites. We evaluated the effect of different anticoagulants and storage conditions on plasma lipids and metabolites plasma samples to make recommendations for the sample collection protocol.

The statistical analysis was performed in total unmatched plasma samples and then further analysis was performed by matching the donors and grouping the samples based on the tube type, sample handling time and temperature. Both the donor-matched and donor-unmatched analysis showed significant differences in lipid profiles between CPT and EDTA-containing samples. Phospholipids were the most affected lipid class. Other affected lipid classes included AcCa, sphingolipids, DGs, TGs, coenzyme, and CEs. Similar studies have been conducted to study the effect of anticoagulants in different biological specimens and mixed results have been reported regarding their effects on metabolite and lipids profiles. For example, PCs and PEs, SMs, TGs and cholesterol were found in higher levels in EDTA-containing plasma vs. citrate-contains plasma which is consistent with our findings [44]. Cholesterol was not covered in our study; however, cholesteryl esters were found to be highly abundant in EDTA-containing plasma relative to citrate-containing plasma. Similarly, Gonzalez-Covarrubias et al. (2013) showed lysophosphatidylcholine (LPC), PCs, SMs, many PEs, and TGs were found to be higher in EDTA-containing plasma samples compared to citrate or heparin suggesting differences may be driven by anticoagulant chemistry, plasma $\mathrm{pH}$, extraction or the electrospray ionization efficiencies of lipids. [53]. The anticoagulant concentration may cause sample dilution due to osmotic effects [54-57] that can potentially affect the metabolite abundance in LC-MS analysis of plasma samples. The osmotic effect draws water out of the red blood cells immediately after contact with blood resulting in dilution of plasma lipids below their actual concentration. This effect, however, was not influenced by processing temperature [56,57].

Heparin is an anti-thrombin activator and EDTA and citrate are metal ions chelators. These chemical components can inactivate the fibrinogen-initiated clotting cascade forming a clot-free blood component, plasma [58]. Though heparin is not detected in the untargeted metabolomics assays, the lithium heparin plasma can form unwanted lithium adducts [59] and boost the ionization efficiency of phospholipids and triacylglycerols including plastic polymers in the collection tube potentially causing serious matrix effects [21]. Several amino acids including aspartate, histidine, and glutamine were observed at higher levels in EDTA-containing plasma and serine was observed in higher levels in citrate-containing plasma in our study. This is in line with previous studies which showed higher amino acid and amine levels in EDTA plasma [44]. The concentrations of phosphoethanolamine, citrulline, cysteine, and tryptophan were observed to increase in EDTA-containing plasma and decrease in citrate-containing plasma when compared with heparin-treated control plasma [27]. As expected, citrate was observed to be higher in citrate-containing tubes. Signal response in LC/MS can also be affected by plasma components, LC tubing interactions, or column active site blocking, etc. Similarly, technical issues might be encountered with small molecule anticoagulants such as a reduction in column lifetime and enhancement of ion suppression, thus making heparin the preferable anticoagulant for metabolomics [47]. 
Table 1. Effect of different physical and chemical parameters on lipids and metabolites in various biological samples.

\begin{tabular}{|c|c|c|c|c|c|c|c|c|c|}
\hline Reference & Year & Material & Method & Time & Temperature & Anticoagulant & Freeze/Thaw & Other & Conclusion \\
\hline Teahan et al. [17] & 2006 & $\begin{array}{l}\text { Serum and } \\
\text { plasma }\end{array}$ & NMR & $2 \mathrm{~h}$ clot time & $\begin{array}{l}\text { Room temperature } \\
\text { and ice }\end{array}$ & Heparin & Yes & & $\begin{array}{l}\text { Variation due to individual. } \\
\text { Freeze-thaw cycle should be minimial, no number of cycle recommended. } \\
\text { Addition of heparin reduced the effect compared to non-heparinated serum or } \\
\text { plasma samples. } \\
\text { Serum clot contact time is the significant factor in introducing variation. } \\
\text { Clotting on ice delayed the effect of temperature. }\end{array}$ \\
\hline Bando et al. [18] & 2010 & $\begin{array}{l}\text { Plasma and } \\
\text { urine }\end{array}$ & GC-MS & NA & $\begin{array}{l}\text { Room temperature } \\
\text { and ice }\end{array}$ & $\begin{array}{l}\text { Plasma: K2EDTA, } \\
\text { Sodium heparin }\end{array}$ & & & $\begin{array}{l}\text { Citrate, 2-oxoglutarate, hippurate, threitol, threonate elevated in } 4 \mathrm{~h} \text { pooled } \\
\text { sample. } \\
\text { Heparinated plasma overlapped with other endogenous metabolites like sugars } \\
\text { potentially causing inter-sample variation. } \\
\text { EDTA did not overlap with other endogenous metabolites. } \\
\text { Recommended the use of EDTA plasma for GC-MS analysis. }\end{array}$ \\
\hline Barri et al. [19] & 2013 & $\begin{array}{l}\text { Serum and } \\
\text { plasma }\end{array}$ & LC-MS & NA & NA & $\begin{array}{l}\text { K2EDTA, Li-Heparin, } \\
\text { Na-citrate }\end{array}$ & & & $\begin{array}{l}\text { Coagulation effect on serum led to release of peptides, hypoxanthine, and } \\
\text { xanthine and can be nullified with robust data processing. } \\
\text { Plasma anticoagulant can lead to ion suppression or enhancement on } \\
\text { metabolites. } \\
\text { Anticoagulant cation can make metabolites dominant in positive ESI/MS mode. } \\
\text { Heparin preferred over others due to no observable matrix effects. } \\
\text { EDTA and citrate plasma elicit sodium and potassium formate cluster causing } \\
\text { ion suppression or enhancement of the coeluting metabolites. } \\
\text { Blood serum is an alternative to avoid the anticoagulant matrix effect in the } \\
\text { plasma sample. }\end{array}$ \\
\hline Yin et al. [22] & 2013 & $\begin{array}{l}\text { Serum and } \\
\text { plasma }\end{array}$ & LC-MS & $2,4,8$, and $24 \mathrm{~h}$ & $\begin{array}{l}\text { Room temperature } \\
\text { and ice }\end{array}$ & Heparin, EDTA & Yes & Hemolysis & 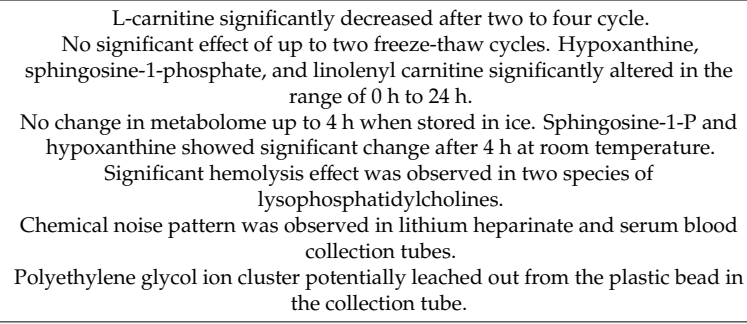 \\
\hline Wandro et al. [23] & 2017 & Sputum & GC-MS & & $4^{\circ} \mathrm{C}$ and $-20^{\circ} \mathrm{C}$ & $\mathrm{NA}$ & Yes & & $\begin{array}{l}\text { Aspartic acid, glycine, isoleucine, serine, and uracil abundance increased after a } \\
\text { day when stored at } 4^{\circ} \mathrm{C} \text {. } \\
\text { No effect at }-20^{\circ} \mathrm{C} \text {. No effect of one to two freeze-thaw cycle. }\end{array}$ \\
\hline Haid et al. [25] & 2018 & Plasma & LC-MS & & $\begin{array}{l}\text { Long term storage } \\
\text { at }-80^{\circ} \mathrm{C}\end{array}$ & NA & & & $\begin{array}{l}\text { Increase in concentration for amino acids, hexoses, butyrylcarnitine, } \\
\text { phospholipids containing more than } 4 \text { carbon. } \\
\text { The decrease in concentration of acylcarnitines, lysophosphatidylcholines, } \\
\text { diacyl-phosphatidylcholines, acyl-alkyl phosphatidylcholines, and } \\
\text { sphingomyelin. }\end{array}$ \\
\hline $\begin{array}{c}\text { Jorgenrud et al. } \\
{[44]}\end{array}$ & 2015 & $\begin{array}{l}\text { Plasma and } \\
\text { serum }\end{array}$ & GC-MS & & $\begin{array}{l}\text { Room temperature } \\
\text { and } 4^{\circ} \mathrm{C}\end{array}$ & EDTA, citrate & & & $\begin{array}{l}\text { Amino acids higher in EDTA plasma, Amines abundance higher in serum and } \\
\text { lowest in citrate plasma. Phenolic compounds abundance highest in EDTA and } \\
\text { lowest in citrate plasma. } \\
\text { Total carboxylic acid higher in citrate plasma compared to EDTA, Sterols, lactic } \\
\text { acid, and serine abundances were lower in citrate compared to EDTA. } \\
\text { No effect of temperature on lipids. }\end{array}$ \\
\hline
\end{tabular}


Table 1. Cont.

\begin{tabular}{|c|c|c|c|c|c|c|c|c|c|}
\hline Reference & Year & Material & Method & Time & Temperature & Anticoagulant & Freeze/Thaw & Other & Conclusion \\
\hline Mei et al. [20] & 2003 & $\begin{array}{l}\text { Serum and } \\
\text { plasma }\end{array}$ & LC-MS & & & $\begin{array}{c}\text { Li-Heparin, } \\
\text { Na-Heparin, } \mathrm{Na}_{2} \text { EDTA }\end{array}$ & & & Li-Heparin and polymers from the container showed matrix effect. \\
\hline $\begin{array}{c}\text { Zivkovic et al. } \\
\text { [45] }\end{array}$ & 2009 & Serum & GC-FID & & $\begin{array}{l}4{ }^{\circ} \mathrm{C},-20^{\circ} \mathrm{C}, \\
-80^{\circ} \mathrm{C}\end{array}$ & & & & $\begin{array}{l}\text { 0-4\% of metabolites affected in most lipid classes when stored for a week at } 4 \\
\qquad{ }^{\circ} \mathrm{C},-20^{\circ} \mathrm{C} \text { and }-80^{\circ} \mathrm{C}\end{array}$ \\
\hline Yu et al. [46] & 2011 & $\begin{array}{l}\text { Serum and } \\
\text { plasma }\end{array}$ & FIA-MS & & & & & & $\begin{array}{l}\text { Reproducibility comparatively better in plasma. Arginine, PC (38:1), LPC (16:0, } \\
\text { 17:0, 18:0, 18:1), serine, phenylalanine, glycine were 20\%-26\% higher in serum } \\
\text { compared to plasma. }\end{array}$ \\
\hline Hebels et al. [47] & 2013 & Plasma & LC-MS & $0 \mathrm{~h}$ to $24 \mathrm{~h}$ & $\begin{array}{l}\text { Room temperature } \\
\text { and }-80^{\circ} \mathrm{C}\end{array}$ & Heparin, EDTA, citrate & & & $\begin{array}{l}\text { No effect of storage time on metabolites. }<1 \% \text { metabolites significantly different } \\
\text { at } \mathrm{FRR}<0.05 \text {. }\end{array}$ \\
\hline Barton et al. [48] & 2008 & $\begin{array}{l}\text { Serum and } \\
\text { urine }\end{array}$ & NMR & $0 \mathrm{~h}$ to $36 \mathrm{~h}$ & & & & & $\begin{array}{l}\text { Plasma and urine metabolic profiles are not affected when stored at } 4{ }^{\circ} \mathrm{C} \text { up to } \\
24 \mathrm{~h} .\end{array}$ \\
\hline Dunn et al. [49] & 2008 & $\begin{array}{l}\text { Serum and } \\
\text { urine }\end{array}$ & GC-MS & $0 \mathrm{~h}$ to $24 \mathrm{~h}$ & & & & & $\begin{array}{l}\text { No significant changes in metabolome was observed at two different storage } \\
\text { time at } 44^{\circ} \mathrm{C} \text {. }\end{array}$ \\
\hline $\begin{array}{l}\text { Heiskanen et al. } \\
\quad[50]\end{array}$ & 2013 & Plasma & $\begin{array}{l}\text { Shotgun } \\
\text { MS }\end{array}$ & $\begin{array}{l}\text { Plasma at }-80 \\
{ }^{\circ} \mathrm{C} \text { monitored } \\
\text { for } 42 \text { months }\end{array}$ & & & & $\begin{array}{l}\text { Plasma sample volume } \\
\quad(5 \text { and } 10 \mu \mathrm{L})\end{array}$ & $\begin{array}{l}\text { The higher plasma volume provided more stability to lipid concentration. } \\
\text { The storage time did not have an effect on lipid stability. }\end{array}$ \\
\hline Gika et al. [51] & 2007 & Urine & LC-MS & 1 month & $\begin{array}{l}\text { Two temperatures } \\
-20^{\circ} \mathrm{C} \text { and }-80^{\circ} \mathrm{C}\end{array}$ & & Yes & $\begin{array}{l}\text { Urine extract in } \\
\text { autosampler for } 20 \mathrm{~h} \text { at } \\
\qquad 4^{\circ} \mathrm{C}\end{array}$ & $\begin{array}{l}\text { No detectable effect on metabolites at two different temperatures for a month. } \\
\text { Sample stable for at least } 20 \mathrm{~h} \text { at } 4^{\circ} \mathrm{C} \text { in the autosampler. } \\
\text { The sample can withstand one to nine freeze-thaw cycles without significant } \\
\text { effect on metabolites. }\end{array}$ \\
\hline Deprez et al. [52] & 2002 & Plasma & NMR & 0-9 month & $\begin{array}{l}4{ }^{\circ} \mathrm{C} \text { and room } \\
\text { temperature }\end{array}$ & & & & $\begin{array}{l}\text { No change in metabolite profile when snap frozen and stored at }-80^{\circ} \mathrm{C} \text { for } \\
9 \text { months. } \\
\text { A significant increase was observed in tyrosine, phenylalanine and glycerol for } \\
\text { the sample at room temperature. } \\
\text { Choline, 3-hydroxybtyurate, acetate, glycerol slightly increase when stored at } 4 \\
{ }^{\circ} \mathrm{C} \text { for } 3-4 \text { days likely due to enzymatic action. }\end{array}$ \\
\hline
\end{tabular}


In our study, plasma samples were collected and stored in EDTA-containing tubes for different time points at $4{ }^{\circ} \mathrm{C}$ and room temperature while citrate-preserved samples were stored only at room temperature. The storage times between sample collection and processing were $0 \mathrm{~h}, 2 \mathrm{~h}, 4 \mathrm{~h}, 8 \mathrm{~h}$ and $24 \mathrm{~h}$ (note: EDTA-containing samples at room temperature and $4{ }^{\circ} \mathrm{C}$ have baseline sample as 0 -h samples). One-way ANOVA and Fisher LSD analyses were performed by grouping and ungrouping the plasma samples by donors. Our analyses showed no significant change in lipid profile across storage times in overall donor-matched analysis however the donor-matched analysis showed several different class of lipids to be affected by storage time. The lipid classes like PC, SM, LPE, and PE were found to be affected due to storage time where the inverse relation between lipid abundance and storage time was observed. Nonetheless, many of the plasma and lipids metabolites were affected by storage temperature. Most of the significantly affected lipids were phospholipids (PEs and LPCs) and were highly abundant in EDTA-treated plasma stored at room temperature. Very few lipids were shown to be higher at $4{ }^{\circ} \mathrm{C}$ and none were MS/MS confirmed. Similar results were observed in metabolites levels where EDTA-treated plasma stored at room temperature show many significantly different metabolites, while very few known metabolites are differentially abundant in EDTA-containing plasma at $4{ }^{\circ} \mathrm{C}$. There is sparse information about the effect of temperature and storage conditions at the metabolite or lipid level though a few studies have been performed to study the effect of long-term storage and temperature on total lipid content in plasma $[45,60,61]$. However, studies showed inconsistent results on the effect of storage and temperature on plasma and serum lipid content. Serum sample storage at $-80^{\circ} \mathrm{C}$ over a year led to a decrease in total cholesterol and triglycerides [45,60-62]. The triglyceride contents of very low-density lipoprotein (VLDL) was found to be stable for 11 weeks of storage at $-20^{\circ} \mathrm{C}$ but decreased beyond this time window [63]. Mean high-density lipoprotein (HDL)-cholesterol levels remain unchanged when stored at $4-6{ }^{\circ} \mathrm{C}$ for 4 days. However, HDL-cholesterol tended to decrease by day 7 and increase by day 14 but this depended upon the initial plasma concentration [64]. In a recent study, $24 \%$ of blood metabolites were found to be significantly affected when stored for $6 \mathrm{~h}$ at room temperature and $21 \%$ of serum metabolites were significantly affected when stored for room temperature for $24 \mathrm{~h} \mathrm{[65].} \mathrm{The} \mathrm{above-mentioned} \mathrm{studies} \mathrm{are} \mathrm{focused} \mathrm{on} \mathrm{lipoproteins,} \mathrm{cholesterol}$ and triglycerides and lack information about the effect of storage and temperature at the lipid species level. With recent advancements in GC/MS and LC/MS, it is now possible to study the lipid content of the plasma at individual lipid species level enabling a deeper understanding the effect of various physical and chemical variables on plasma lipid and metabolite profiles. GC-MS based untargeted metabolomics studies of sputum samples maintained stability for 8 weeks at $-20^{\circ} \mathrm{C}$ and $-80^{\circ} \mathrm{C}$ while metabolite abundance changed after one day at $4{ }^{\circ} \mathrm{C}$ [23]. An NMR based metabolomics study showed that the change in energy-related metabolites was retarded when plasma samples were processed on ice [17]. In another study, EDTA-containing blood samples showed stability up to $4 \mathrm{~h}$ when processed in ice-cold water and withstand the effects of 4 freeze-thaw cycles with only slight changes in metabolome; however, hypoxanthine and sphingosine 1-phosphate were significantly affected with an increase of $1810 \%$ and $710 \%$ respectively when stored at room temperature for $2 \mathrm{~h}$ [22]. This study did not assess the effect of the freeze-thaw cycles and many commonly used anticoagulants; however, other studies $[19,49]$ recommend the use of heparin for LC-MS-based metabolomics contrasting the recommendation made by Yuille et al. (2010) [66] which details a wide range of freeze-thaw cycle (2-10 freeze-cycles) without significant effect on metabolites [22,23,67-69] One LC-MS/MS-based study showed a linear increase (approximately $50 \%$ ) of heparin whole blood choline concentration during storage for $>4 \mathrm{~h}$ whereas the choline concentration in EDTA whole blood increased for an hour and then stabilized [70]. Stability assessment of total cholesterol, high-density lipoprotein cholesterol and triglycerides of human serum stored at $-15{ }^{\circ} \mathrm{C}$ for 18 weeks showed no significant change in concentration [71]. Similarly, photometry based assays showed lipids and polar metabolites such as bilirubin, glucose, cholesterol, triglycerides, and high-density lipoprotein remained stable at $-20^{\circ} \mathrm{C}$ for up to three months and withstood the effect of up to 10 freeze-thaw cycles [67]. Several metabolites such as betain, sarcosine, and creatinine were relatively stable whereas methionine and most $B$ vitamins 
were susceptible to oxidative degradation during long term storage at $-25^{\circ} \mathrm{C}$ [21]. Long term storage of unsaturated fatty acids, especially eicosapentanoic acid (EPA) and docosahexanoic acid (DHA), increases oxidative damage and can be reduced by freezing and treating blood with heparin due to its antioxidant properties [21,72,73]. Most hormones should be collected in EDTA-containing tubes and transported and stored at $4{ }^{\circ} \mathrm{C}$ with the exception of adrenocorticotrophic hormone (ACTH) which requires frozen transport and storage [26]. NMR based metabolomics showed that urine and serum can be stored up to $24 \mathrm{~h}$ at $4{ }^{\circ} \mathrm{C}$ with undetectable changes in metabolite profile [49].

Anticoagulants affect the metabolome and lipidome of biological specimens; however, findings from different studies are not consistently aligned offering no concrete general guidelines for sample collection and processing prior to LC-MS (Summarized in Table 1). Studying collection-related variables upon the lipidome and metabolome provides insights into understanding the potential for sample collection and processing artifact. This can help design collection and processing techniques to minimize these potential disturbances in clinical studies (e.g., vaccine studies). Based on our findings the following recommendations were made for sample collection, processing, handling, and preservation. We recommend using EDTA as an anticoagulant over citrate. It is always recommended to limit the freeze-thaw cycle of biological samples. We recommend low-temperature processing and handling for blood though no significant temperature-induced changes were observed in this study. We did not observe serious effects on lipidome and metabolome profile until $24 \mathrm{~h}$ prior to flash freezing. However, it is highly recommended that the blood collection and processing should be completed performed at the lowest possible temperature and preserved at $-80{ }^{\circ} \mathrm{C}$ within $24 \mathrm{~h}$. It is important that metabolomics and lipidomics studies report the specimen collection parameters such as tube type, processing time and temperature to ensure that results can be adjusted to account for artificial collection or processing-induced variability.

\section{Conclusions}

The effect of storage temperature, storage time, and anticoagulant on the plasma lipidome and metabolome were studied in healthy donors. From this study, we found that the lipidome was not significantly affected when plasma was stored at $4{ }^{\circ} \mathrm{C}$ or room temperature until $24 \mathrm{~h}$. However, anticoagulant had significant effects in plasma lipid profiles. Very few metabolites were affected due to temperature differences. Several studies have shown inconsistent findings in terms of the effect of temperature, storage time, anticoagulants, and freeze-thaw cycles on metabolites and lipids profiles though many of the studies consistently align with the conclusion of their findings. Nonetheless, the effect of various physical and chemical parameters on biological specimens is debatable and without solid explanation. It is possible that several changes occur during sample collection, processing, and handling that can potentially introduce unwanted variability. Many of those critical parameters depend upon the distance of the sample collection to sample processing sites, availability of resources for sample processing and preservation, time lag during sample collection, processing, shipping, and extraction. Thus the efforts should be directed to find study-dependent critical parameters. Depending on the sample type, analytical methods, and overall processing steps, it is the researchers' responsibility to determine critical parameters that could introduce variability and need to be investigated before initiating the clinical study. Overall, we recommend that the samples should be collected in EDTA-containing tubes and that all the processing work before freezing at $-80^{\circ} \mathrm{C}$ should be completed within $24 \mathrm{~h}$ while maintaining the temperature of $4{ }^{\circ} \mathrm{C}$. This study did not investigate the mechanism behind the effects of anticoagulant type on plasma lipids though several potential explanations have been proposed. Further studies should be directed toward understanding the mechanism behind the differential anticoagulant effects, temperature effects, and storage effects on plasma lipids and metabolites.

Supplementary Materials: The following are available online http://www.mdpi.com/2218-273X/9/5/200/s1. There are six supplementary files (four zipped files and two pdf files). Supplementary Material 1: The zipped folder contains two excel files and one. docx file. Readme (.docx) file contains information about the two excel 
files. The excel file contains results of One way ANOVA with Fisher LSD test for the donor-unmatched positive mode lipidomics and metabolomics data grouped by anticoagulants. Supplementary Materials 2: The zipped folder contains eleven excel files and one. docx file. Readme (.docx) file contains information about the eleven excel files. The excel file contains results of One way ANOVA with Fisher LSD test for the donor-unmatched and donor-matched negative mode lipidomics and metabolomics data grouped by anticoagulants. Supplementary Material 3: The zipped folder contains nine excel files and one.docx file. Readme (.docx) file contains information about the nine excel files. The excel file contains results of One way ANOVA with Fisher LSD test for the donor-matched positive mode lipidomics and metabolomics data grouped by anticoagulants. Supplementary Materials 4: The zipped folder contains eight excel files and one.docx file. Readme (.docx) file contains information about the eight excel files. The excel file contains results of One way ANOVA with Fisher LSD test for the donor-matched negative mode lipidomics and metabolomics data grouped by storage time. Supplementary Materials 5: The supplementary material 5 is a pdf file for lipidomics showing base peak ion chromatograms for quality standard and plasma sample in positive and negative ionization mode. Supplementary Materials 6: The supplementary material 6 is a pdf file for metabolomics showing base peak ion chromatograms for quality standard and plasma sample in positive and negative ionization mode.

Author Contributions: Conceptualization; M.S.; Methodology, M.K., K.M.M.-S., J.K.C., V.T.; Data acquisition, D.A.G., V.T.; Data analysis, M.K., A.T.; Investigation, M.S.; Resources, M.J.M.; Writing-Original Draft, M.K., J.K.C.; Writing-Review and editing, M.K., E.A.O., J.K.C., E.J.A., M.J.M., E.J.A., C.M., N.R.; Supervision, M.S., E.A.O., S.L.; Project administration, M.J.M., M.N., N.R., C.M.; Funding acquisition, M.S., M.J.M.

Funding: This study was supported in part by the Emory Integrated Lipidomics Core (EILC), which is subsidized by the Emory University School of Medicine and is one of the Emory Integrated Core Facilities. This work was supported by awards from the Division of Microbiology and Infectious Diseases, National Institute of Allergy and Infectious Diseases at the National Institutes of Health to Emory Vaccine and Treatment Evaluation Unit, contract HHSN272201300018I. This work was supported by the Georgia Institute of Technology's Mass Spectrometry Core Facility.

Acknowledgments: We thank the Emory VTEU administrative and finance core for their support including Dean Kleinhenz, Hannah Huston, Michele Paine McCullough. We also thank Robert Johnson, NIAID Division of Microbiology and Infectious Diseases (DMID). Additional support was provided by the Georgia Clinical and Translational Science Alliance of the National Institutes of Health under Award Number UL1TR002378. The content is solely the responsibility of the authors and does not necessarily reflect the official views of the National Institutes of Health.

Conflicts of Interest: The authors declare no conflict of interest.

\section{References}

1. Lagarde, M.; Geloen, A.; Record, M.; Vance, D.; Spener, F. Lipidomics Is Emerging. Biochim. Et Biophys. Acta (Bba)_Bioenerg. 2003, 1634, 61. [CrossRef]

2. Oliver, S.G. Functional Genomics: Lessons from Yeast. Philos Trans. R Soc. Lond B Biol. Sci. 2002, 357, 17-23. [CrossRef] [PubMed]

3. Wishart, D.S.; Feunang, Y.D.; Marcu, A.; Guo, A.C.; Liang, K.; Vazquez-Fresno, R.; Sajed, T.; Johnson, D.; Li, C.; Karu, N.; et al. Hmdb 4.0: The Human Metabolome Database for 2018. Nucleic Acids Res. 2017, 46, D608-D617. [CrossRef] [PubMed]

4. Brown, D.A.; London, E. Functions of Lipid Rafts in Biological Membranes. Annu. Rev. Cell Dev. Biol. 1998, 14, 111-136. [CrossRef] [PubMed]

5. Ghosh, S.; Strum, J.C.; Bell, R.M. Lipid Biochemistry: Functions of Glycerolipids and Sphingolipids in Cellular Signaling. Faseb J. 1997, 11, 45-50. [CrossRef] [PubMed]

6. Gorgas, K.; Teigler, A.; Komljenovic, D.; Just, W.W. The Ether Lipid-Deficient Mouse: Tracking Down Plasmalogen Functions. Biochim. Et Biophys. Acta (Bba)-Bioenerg. 2006, 1763, 1511-1526. [CrossRef]

7. Ikeda, M.; Kihara, A.; Igarashi, Y. Lipid Asymmetry of the Eukaryotic Plasma Membrane: Functions and Related Enzymes. Biol. Pharm. Bull. 2006, 29, 1542-1546. [CrossRef]

8. Olzmann, J.A.; Carvalho, P. Dynamics and Functions of Lipid Droplets. Nat. Rev. Mol. Cell Biol. 2018. [CrossRef]

9. Sillence, D.J. New Insights into Glycosphingolipid Functions-Storage, Lipid Rafts, and Translocators. Int. Rev. Cytol. 2007, 262, 151-189. [PubMed]

10. Tazoe, F.; Yagyu, H.; Ishibashi, S. Functions of Enzymes Involved in Lipid Metabolism. Nihon Rinsho. Jpn. J. Clin. Med. 2007, 65, 26-30. 
11. Wanders, R.J.; van Grunsven, E.G.; Jansen, G.A. Lipid Metabolism in Peroxisomes: Enzymology, Functions and Dysfunctions of the Fatty Acid Alpha- and Beta-Oxidation Systems in Humans. Biochem. Soc. Trans. 2000, 28, 141-149. [CrossRef] [PubMed]

12. Han, X. Lipidomics for Studying Metabolism. Nat. Rev. Endocrinol. 2016, 12, 668-679. [CrossRef] [PubMed]

13. Finkelstein, J.; Heemels, M.T.; Shadan, S.; Weiss, U. Lipids in Health and Disease. Nature 2014, $510,47$. [CrossRef]

14. Muro, E.; Atilla-Gokcumen, G.E.; Eggert, U.S. Lipids in Cell Biology: How Can We Understand Them Better? Mol. Biol. Cell 2014, 25, 1819-1823. [CrossRef] [PubMed]

15. Mooradian, A.D. Dyslipidemia in Type 2 Diabetes Mellitus. Nat. Clin. Pract. : Endocrinol. Metab. 2009, 5, 150-159. [CrossRef] [PubMed]

16. Saghatelian, A.; Cravatt, B.F. Global Strategies to Integrate the Proteome and Metabolome. Curr. Opin. Chem. Biol. 2005, 9, 62-68. [CrossRef]

17. Teahan, O.; Gamble, S.; Holmes, E.; Waxman, J.; Nicholson, J.K.; Bevan, C.; Keun, H.C. Impact of Analytical Bias in Metabonomic Studies of Human Blood Serum and Plasma. Anal. Chem. 2006, 78, 4307-4318. [CrossRef] [PubMed]

18. Bando, K.; Kawahara, R.; Kunimatsu, T.; Sakai, J.; Kimura, J.; Funabashi, H.; Seki, T.; Bamba, T.; Fukusaki, E. Influences of Biofluid Sample Collection and Handling Procedures on Gc-Ms Based Metabolomic Studies. J. Biosci. Bioeng. 2010, 110, 491-499. [CrossRef]

19. Barri, T.; Dragsted, L.O. Uplc-Esi-Qtof/Ms and Multivariate Data Analysis for Blood Plasma and Serum Metabolomics: Effect of Experimental Artefacts and Anticoagulant. Anal. Chim. Acta 2013, 768, 118-128. [CrossRef]

20. Mei, H.; Hsieh, Y.; Nardo, C.; Xu, X.; Wang, S.; Ng, K.; Korfmacher, W.A. Investigation of Matrix Effects in Bioanalytical High-Performance Liquid Chromatography/Tandem Mass Spectrometric Assays: Application to Drug Discovery. Rapid Commun. Mass Spectrom 2003, 17, 97-103. [CrossRef]

21. Yin, P.; Lehmann, R.; Xu, G. Effects of Pre-Analytical Processes on Blood Samples Used in Metabolomics Studies. Anal. Bioanal Chem. 2015, 407, 4879-4892. [CrossRef]

22. Yin, P.; Peter, A.; Franken, H.; Zhao, X.; Neukamm, S.S.; Rosenbaum, L.; Lucio, M.; Zell, A.; Haring, H.U.; $\mathrm{Xu}, \mathrm{G}$; et al. Preanalytical Aspects and Sample Quality Assessment in Metabolomics Studies of Human Blood. Clin. Chem. 2013, 59, 833-845. [CrossRef] [PubMed]

23. Wandro, S.; Carmody, L.; Gallagher, T.; LiPuma, J.J.; Whiteson, K. Making It Last: Storage Time and Temperature Have Differential Impacts on Metabolite Profiles of Airway Samples from Cystic Fibrosis Patients. Msystems 2017, 2. [CrossRef] [PubMed]

24. Hernandes, V.V.; Barbas, C.; Dudzik, D. A Review of Blood Sample Handling and Pre-Processing for Metabolomics Studies. Electrophoresis 2017, 38, 2232-2241. [CrossRef] [PubMed]

25. Haid, M.; Muschet, C.; Wahl, S.; Romisch-Margl, W.; Prehn, C.; Moller, G.; Adamski, J. Long-Term Stability of Human Plasma Metabolites During Storage at -80 Degrees C. J. Proteome Res. 2018, 17, 203-211. [CrossRef]

26. Evans, M.J.; Livesey, J.H.; Ellis, M.J.; Yandle, T.G. Effect of Anticoagulants and Storage Temperatures on Stability of Plasma and Serum Hormones. Clin. Biochem. 2001, 34, 107-112. [CrossRef]

27. Chuang, C.K.; Lin, S.P.; Lin, Y.T.; Huang, F.Y. Effects of Anticoagulants in Amino Acid Analysis: Comparisons of Heparin, Edta, and Sodium Citrate in Vacutainer Tubes for Plasma Preparation. Clin. Chem. 1998, 44, 1052-1056.

28. Lopez-Bascon, M.A.; Calderon-Santiago, M.; Sanchez-Ceinos, J.; Fernandez-Vega, A.; Guzman-Ruiz, R.; Lopez-Miranda, J.; Malagon, M.M.; Priego-Capote, F. Influence of Sample Preparation on Lipidomics Analysis of Polar Lipids in Adipose Tissue. Talanta 2018, 177, 86-93. [CrossRef] [PubMed]

29. Bernini, P.; Bertini, I.; Luchinat, C.; Nincheri, P.; Staderini, S.; Turano, P. Standard Operating Procedures for Pre-Analytical Handling of Blood and Urine for Metabolomic Studies and Biobanks. J. Biomol. Nmr 2011, 49, 231-243. [CrossRef]

30. Bligh, E.G.; Dyer, W.J. A Rapid Method of Total Lipid Extraction and Purification. Can. J. Biochem. Physiol. 1959, 37, 911-917. [CrossRef]

31. Soltow, Q.A.; Strobel, F.H.; Mansfield, K.G.; Wachtman, L.; Park, Y.; Jones, D.P. High-Performance Metabolic Profiling with Dual Chromatography-Fourier-Transform Mass Spectrometry (Dc-Ftms) for Study of the Exposome. Metabolomics 2013, 9, S132-S143. [CrossRef] [PubMed] 
32. Go, Y.M.; Walker, D.I.; Liang, Y.; Uppal, K.; Soltow, Q.A.; Tran, V.; Strobel, F.; Quyyumi, A.A.; Ziegler, T.R.; Pennell, K.D.; et al. Reference Standardization for Mass Spectrometry and High-Resolution Metabolomics Applications to Exposome Research. Toxicol Sci. 2015, 148, 531-543. [CrossRef] [PubMed]

33. Pluskal, T.; Castillo, S.; Villar-Briones, A.; Oresic, M. Mzmine 2: Modular Framework for Processing, Visualizing, and Analyzing Mass Spectrometry-Based Molecular Profile Data. BMC Bioinform. 2010, 11, 395. [CrossRef]

34. Katajamaa, M.; Miettinen, J.; Oresic, M. Mzmine: Toolbox for Processing and Visualization of Mass Spectrometry Based Molecular Profile Data. Bioinformatics 2006, 22, 634-636. [CrossRef] [PubMed]

35. Fahy, E.; Sud, M.; Cotter, D.; Subramaniam, S. Lipid Maps Online Tools for Lipid Research. Nucleic Acids Res. 2007, 35, W606-W612. [CrossRef]

36. Koelmel, J.P.; Kroeger, N.M.; Ulmer, C.Z.; Bowden, J.A.; Patterson, R.E.; Cochran, J.A.; Beecher, C.W.W.; Garrett, T.J.; Yost, R.A. Lipidmatch: An Automated Workflow for Rule-Based Lipid Identification Using Untargeted High-Resolution Tandem Mass Spectrometry Data. BMC Bioinform. 2017, 18. [CrossRef]

37. Fahy, E.; Subramaniam, S.; Murphy, R.C.; Nishijima, M.; Raetz, C.R.; Shimizu, T.; Spener, F.; van Meer, G.; Wakelam, M.J.; Dennis, E.A. Update of the Lipid Maps Comprehensive Classification System for Lipids. J. Lipid Res. 2009, 50, S9-S14. [CrossRef] [PubMed]

38. Yu, T.; Park, Y.; Johnson, J.M.; Jones, D.P. Aplcms-Adaptive Processing of High-Resolution Lc/Ms Data. Bioinformatics 2009, 25, 1930-1936. [CrossRef]

39. Uppal, K.; Soltow, Q.A.; Strobel, F.H.; Pittard, W.S.; Gernert, K.M.; Yu, T.; Jones, D.P. Xmsanalyzer: Automated Pipeline for Improved Feature Detection and Downstream Analysis of Large-Scale, Non-Targeted Metabolomics Data. BMC Bioinform. 2013, 14, 15. [CrossRef]

40. Uppal, K.; Walker, D.I.; Jones, D.P. Xmsannotator: An R Package for Network-Based Annotation of High-Resolution Metabolomics Data. Anal. Chem. 2017, 89, 1063-1067. [CrossRef]

41. Xia, J.; Psychogios, N.; Young, N.; Wishart, D.S. Metaboanalyst: A Web Server for Metabolomic Data Analysis and Interpretation. Nucleic Acids Res. 2009, 37, W652-W660. [CrossRef] [PubMed]

42. Xia, J.; Wishart, D.S. Using Metaboanalyst 3.0 for Comprehensive Metabolomics Data Analysis. Curr. Protoc. Bioinform. 2016, 55, 14101-141091. [CrossRef] [PubMed]

43. Chong, J.; Soufan, O.; Li, C.; Caraus, I.; Li, S.; Bourque, G.; Wishart, D.S.; Xia, J. Metaboanalyst 4.0: Towards More Transparent and Integrative Metabolomics Analysis. Nucleic Acids Res. 2018, 46, W486-W494. [CrossRef] [PubMed]

44. Jorgenrud, B.; Jantti, S.; Mattila, I.; Poho, P.; Ronningen, K.S.; Yki-Jarvinen, H.; Oresic, M.; Hyotylainen, T. The Influence of Sample Collection Methodology and Sample Preprocessing on the Blood Metabolic Profile. Bioanalysis 2015, 7, 991-1006. [CrossRef] [PubMed]

45. Zivkovic, A.M.; Wiest, M.M.; Nguyen, U.; Nording, M.L.; Watkins, S.M.; German, J.B. Assessing Individual Metabolic Responsiveness to a Lipid Challenge Using a Targeted Metabolomic Approach. Metabolomics 2009, 5, 209-218. [CrossRef]

46. Yu, Z.; Kastenmuller, G.; He, Y.; Belcredi, P.; Moller, G.; Prehn, C.; Mendes, J.; Wahl, S.; Roemisch-Margl, W.; et al. Differences between Human Plasma and Serum Metabolite Profiles. PLoS ONE 2011, 6, e21230. [CrossRef] [PubMed]

47. Hebels, D.G.; Georgiadis, P.; Keun, H.C.; Athersuch, T.J.; Vineis, P.; Vermeulen, R.; Portengen, L.; Bergdahl, I.A.; Hallmans, G.; et al. Kyrtopoulos, and Consortium EnviroGenomarkers Project. Performance in Omics Analyses of Blood Samples in Long-Term Storage: Opportunities for the Exploitation of Existing Biobanks in Environmental Health Research. Env. Health Perspect 2013, 121, 480-487. [CrossRef]

48. Barton, R.H.; Nicholson, J.K.; Elliott, P.; Holmes, E. High-Throughput 1h Nmr-Based Metabolic Analysis of Human Serum and Urine for Large-Scale Epidemiological Studies: Validation Study. Int. J. Epidemiol. 2008, 37, 31-40. [CrossRef]

49. Dunn, W.B.; Broadhurst, D.; Ellis, D.I.; Brown, M.; Halsall, A.; O’Hagan, S.; Spasic, I.; Tseng, A.; Kell, D.B. A Gc-Tof-Ms Study of the Stability of Serum and Urine Metabolomes During the Uk Biobank Sample Collection and Preparation Protocols. Int. J. Epidemiol. 2008, 37, 23-30. [CrossRef]

50. Heiskanen, L.A.; Suoniemi, M.; Ta, H.X.; Tarasov, K.; Ekroos, K. Long-Term Performance and Stability of Molecular Shotgun Lipidomic Analysis of Human Plasma Samples. Anal. Chem. 2013, 85, 8757-8763. [CrossRef] 
51. Gika, H.G.; Theodoridis, G.A.; Wingate, J.E.; Wilson, I.D. Within-Day Reproducibility of an Hplc-Ms-Based Method for Metabonomic Analysis: Application to Human Urine. J. Proteome Res. 2007, 6, 3291-3303. [CrossRef]

52. Deprez, S.; Sweatman, B.C.; Connor, S.C.; Haselden, J.N.; Waterfield, C.J. Optimisation of Collection, Storage and Preparation of Rat Plasma for $1 \mathrm{~h}$ Nmr Spectroscopic Analysis in Toxicology Studies to Determine Inherent Variation in Biochemical Profiles. J. Pharm. Biomed. Anal. 2002, 30, 1297-1310. [CrossRef]

53. Gonzalez-Covarrubias, V.; Dane, A.; Hankemeier, T.; Vreeken, R.J. The Influence of Citrate, Edta, and Heparin Anticoagulants to Human Plasma Lc-Ms Lipidomic Profiling. Metabolomics 2013, 9, 337-348. [CrossRef]

54. Goossens, W.; Van Duppen, V.; Verwilghen, R.L. K2- or K3-Edta: The Anticoagulant of Choice in Routine Haematology? Clin. Lab. Haematol. 1991, 13, 291-295. [CrossRef]

55. Lippi, G.; Giampaolo, L.; Guidi, G. Effects of Anticoagulants on Lipoprotein(a) Measurements with Four Commercial Assays. Eur. J. Clin. Chem. Clin. Biochem. 1996, 34, 251-255. [CrossRef] [PubMed]

56. Boyd, E.M.; Murray, R.B. The Lipid Content of Leucocytes from Heparinized Blood. Cmaj: Can. Med. Assoc. J. 1937, 37, 229-231.

57. Eldon, M.B.; Ronald, B.M. The Effect of Anticoagulants on Blood Lipids. J. Biol. Chem. 1937, 117, $629-638$.

58. Denery, J.R.; Nunes, A.A.; Dickerson, T.J. Characterization of Differences between Blood Sample Matrices in Untargeted Metabolomics. Anal. Chem. 2011, 83, 1040-1047. [CrossRef] [PubMed]

59. Kirwan, J.A.; Brennan, L.; Broadhurst, D.; Fiehn, O.; Cascante, M.; Dunn, W.B.; Schmidt, M.A.; Velagapudi, V. Preanalytical Processing and Biobanking Procedures of Biological Samples for Metabolomics Research: A White Paper, Community Perspective (for Precision Medicine and Pharmacometabolomics Task Group-the Metabolomics Society Initiative). Clin. Chem. 2018, 64, 1158-1182. [CrossRef]

60. Devanapalli, B.; Bermingham, M.A.; Mahajan, D. Effect of Long-Term Storage at- 80 Degrees C on the Various Lipid Parameters in Stored Plasma Samples. Clin. Chim. Acta 2002, 322, 179-181. [CrossRef]

61. Reckless, J.P.D.; Betteridge, D.J.; Wu, P.; Payne, B.; Galton, D.J. Effect of Storage on Plasma-Lipoproteins. Lancet 1977, 2, 350. [CrossRef]

62. Shih, W.J.; Bachorik, P.S.; Haga, J.A.; Myers, G.L.; Stein, E.A. Estimating the Long-Term Effects of Storage at-70 Degrees C on Cholesterol, Triglyceride, and Hdl-Cholesterol Measurements in Stored Sera. Clin. Chem. 2000, 46, 351-364.

63. Tiedink, H.G.M.; Katan, M.B. Variability in Lipoprotein Concentrations in Serum after Prolonged Storage at -20-Degrees-C. Clin. Chim. Acta 1989, 180, 147-155. [CrossRef]

64. Bachorik, P.S.; Walker, R.; Brownell, K.D.; Stunkard, A.J.; Kwiterovich, P.O. Determination of High Density Lipoprotein-Cholesterol in Stored Human Plasma. J. Lipid Res. 1980, 21, 608-616.

65. Kamlage, B.; Neuber, S.; Bethan, B.; Gonzalez Maldonado, S.; Wagner-Golbs, A.; Peter, E.; Schmitz, O.; Schatz, P. Impact of Prolonged Blood Incubation and Extended Serum Storage at Room Temperature on the Human Serum Metabolome. Metabolites 2018, 8, 6. [CrossRef] [PubMed]

66. Yuille, M.; Illig, T.; Hveem, K.; Schmitz, G.; Hansen, J.; Neumaier, M.; Tybring, G.; Wichmann, E.; Ollier, B. Laboratory Management of Samples in Biobanks: European Consensus Expert Group Report. Biopreserv Biobank 2010, 8, 65-69. [CrossRef]

67. Cuhadar, S.; Koseoglu, M.; Atay, A.; Dirican, A. The Effect of Storage Time and Freeze-Thaw Cycles on the Stability of Serum Samples. Biochem. Med. Cas. Hrvat. Drus. Med. Biokem. 2013, 23, 70-77. [CrossRef]

68. Pinto, J.; Domingues, M.R.M.; Galhano, E.; Pita, C.; Almeida, M.D.; Carreira, I.M.; Gil, A.M. Human Plasma Stability During Handling and Storage: Impact on Nmr Metabolomics. Analyst 2014, 139, 1168-1177. [CrossRef]

69. Lee, J.E.; Kim, S.Y.; Shin, S.Y. Effect of Repeated Freezing and Thawing on Biomarker Stability in Plasma and Serum Samples. Osong Public Health Res. Perspect 2015, 6, 357-362. [CrossRef]

70. Yue, B.E.; Pattison, E.; Roberts, W.L.; Rockwood, A.L.; Danne, O.; Danne, O.; Lueders, C.; Mockel, M. Choline in Whole Blood and Plasma: Sample Preparation and Stability. Clin. Chem 2008, 54, 590-593. [CrossRef]

71. Stokes, Y.M.; Salmond, C.E.; Carpenter, L.M.; Welby, T.J. Stability of Total Cholesterol, High-DensityLipoprotein Cholesterol, and Triglycerides in Frozen Sera. Clin. Chem. 1986, 32, 995-999. [PubMed] 
72. Pottala, J.V.; Espeland, M.A.; Polreis, J.; Robinson, J.; Harris, W.S. Correcting the Effects of -20 Degrees C Storage and Aliquot Size on Erythrocyte Fatty Acid Content in the Women's Health Initiative. Lipids 2012, 47, 835-846. [CrossRef] [PubMed]

73. Metherel, A.H.; Aristizabal Henao, J.J.; Stark, K.D. Epa and Dha Levels in Whole Blood Decrease More Rapidly When Stored at -20 Degrees C as Compared with Room Temperature, 4 and -75 Degrees C. Lipids 2013, 48, 1079-1091. [CrossRef] [PubMed]

(C) 2019 by the authors. Licensee MDPI, Basel, Switzerland. This article is an open access article distributed under the terms and conditions of the Creative Commons Attribution (CC BY) license (http://creativecommons.org/licenses/by/4.0/). 